\title{
1 Dispersal ability predicts evolutionary success among mammalian carnivores
}

2 Authors: S. Faurby ${ }^{1,2, *}$, L. Werdelin ${ }^{3}$, A. Antonelli ${ }^{1,2,4}$

\section{Affiliations:}

$4 \quad{ }^{1}$ Department of Biological and Environmental Sciences, University of Gothenburg, Box 461, SE

5 40530, Göteborg, Sweden

$6 \quad{ }^{2}$ Gothenburg Global Biodiversity Centre, Box 461, SE 40530 Göteborg, Sweden

$7 \quad{ }^{3}$ Swedish Museum of Natural History, Department of Palaeobiology, Box 50007, SE 10405

8 Stockholm, Sweden

$9 \quad{ }^{4}$ Royal Botanic Gardens, Kew, TW9 3AE, Richmond, Surrey, UK

*Correspondence to: Soren.Faurby@bioenv.gu.se

\section{Abstract}

Understanding why some clades contain more species than others is a major challenge in evolutionary biology, and variation in dispersal ability and its connection to diversification rate may be part of the explanation. Several studies have suggested a negative relationship between dispersal capacity and diversification rate among living mammals. However, this pattern may differ when also considering extinct species, given known extinction biases. The colonization of new areas by various lineages may be associated with both diversity increases in those colonising lineages and declines in the lineages already present. Past diversity declines are, however, effectively impossible to infer based on phylogenies of extant taxa, and the underlying process may, therefore, be difficult to determine. Here we produce a novel species-level phylogeny of all known extant and extinct species of the order Carnivora and related extinct groups (1,723 species in total) to show that there is instead a positive relationship between dispersal rate and diversification rate when all extinct species are included. Species that disperse between continents leave more descendant species than non-dispersers, and dispersing species belong to lineages that at the time of dispersal were diversifying faster than the average non-disperser. Our study showcases the importance of combining fossils and phylogenies to better understand evolutionary and biogeographic patterns. 


\section{Introduction}

Clades from across the tree of life vary widely in both diversification rate and in the dispersal capacity

of the species they comprise, but the extent to which the variation in the two is coupled remains unclear. Among extant vertebrates, a limited number of clades show substantially higher diversification rates than others (1). The fossil record also shows that vertebrate classes vary widely in how many families of equal ages they contain (2). The variation in dispersal capacity among extant vertebrates is equally evident. Some species have colonised nearly the entire world. At one extreme, the range of the wild horse (Equus ferus) spanned five continents including northern Africa, the whole of Eurasia and most of the Americas until the end of the last ice age (3). At the other extreme, we find the lemur genus Eulemur in Madagascar, where even minor rivers have restricted the migration of individuals sufficiently to result in individual species that are endemic to small areas between neighbouring rivers (4). Interestingly, the clades encompassing these two examples have identical numbers of species (12; sensu [3]), at least when the extinct Late Pleistocene species of horses are included (Equidae: Equus, Haringtonhippus, and Hippidion). These two clades also have similar ages (the most recent common ancestor [MRCA] of the lemur genus is $\sim 4.5$ million years [My] old following (4); the MRCA of the horses is $~ 6 \mathrm{My}$ following [5]). Taken together, there is thus no universal relationship between dispersal rate and diversification rate.

There are, however, strong arguments for why a relationship between dispersal rate and diversification rate should be expected. A negative correlation between the two rates may be generated under purely neutral models (see e.g. [6]). This is because the in situ per area speciation rates would normally increase with decreasing dispersal rates, since populations of poorly dispersing organisms can more readily become isolated from each other and eventually speciate. While a negative relationship is most likely based on neutral models, arguments could also be made for a positive relationship. Increased dispersal rate could potentially increase diversification rate by increasing the total area occupied by the clade, but empirical support for such an effect is limited (7). 
models based on interspecific competition (hereafter non-neutral models). A common pattern is a waxand-wane model with increases followed by decreases in diversity within each clade (e.g. 8,9$)$. If this is driven by competition, it should produce increased diversity for species with higher dispersal rates, both at the time of diversity increase and the time of diversity decline. During the period of increased diversity, species with a higher dispersal rate would be faster at colonizing all the areas formerly occupied by the species of a clade that they are outcompeting. During their global decline, species with a higher dispersal ability would be able to survive in peripheral regions by escaping direct contact with their competitors.

Although the expectations for non-neutral models have not been explicitly tested, there is anecdotal support based on distribution data, at least when fossils are included. The clearest examples come from the isolated archipelago of New Zealand, where both the Tuatara (Sphenodon spp.) and the only known non-flying mammal native to those islands (an unnamed Miocene species often referred to as the Saint Bathans mammal) represent the last remnants of formerly far more diverse and widespread clades $(1,10)$. There is also evidence of large geographic ranges for some rapidly diversifying lineages, presumably in their expanding phase, such as the Pacific flying foxes (Pteropus spp.) (11), but the latter pattern could be generated under both a neutral and a non-neutral model. The expectations from these non-neutral models are also seen in macro-evolutionary analyses of the fossil record. Among mammalian carnivores, there is evidence that the decline in some older clades may be causally related, through increased competition, to the net diversification of younger clades $(12,13)$.

To reliably tease apart the different mechanisms operating under the neutral and nonneutral models, we may need data on both the diversification rate at the time of dispersal and on the number of descendants each species leaves after dispersal. If diversification rate is increased through increased colonization rate, good dispersers would leave more descendant species than poor dispersers, but they would be unlikely to have a high diversification rate at the time of dispersal in their source area, as discussed above. On the other hand, if non-neutral models prevail, better competitors would both be diversifying faster in their source area and leaving a larger number of 
descendant species after successful colonization. The required information to test these predictions has, to the best of our knowledge, not yet been assembled.

With few but increasing exceptions (e.g 13,14), macro-evolutionary studies to date have been based on phylogenies comprised solely of extant species, where the amount of information often makes it impossible to determine if clades are in diversity decline, or show positive yet densitydependent diversification (15). It has even been suggested that estimation of extinction rates relying solely on extant taxa may not be possible $(16,17)$. Such problems may be avoided for analyses relying solely on fossil data (18). On the other hand, the exclusion of a phylogenetic tree in such analyses usually only allows for comparison of the diversification rates within pre-defined taxonomic entities like families (see e.g. (13)), unlike tree-based analyses where comparisons can be made between any named or unnamed clades. A combined approach based on phylogenetic trees but also incorporating all suitable fossils may, therefore, be optimal for inferring macro-evolutionary patterns $(14,19,20)$.

Here we test the relationship between diversification and transcontinental dispersal rates in mammals by combining the advantages of tree-based and fossil-based methods. We build and analyse a complete species-level phylogeny of all extant and extinct species of mammalian carnivores and related extinct groups (Carnivoramorpha, Hyaenodonta, and Oxyaenidae). Our results provide unequivocal evidence that species with high dispersal capacity both had a higher diversification rate at the time of dispersal and left more descendant species than the species that did not disperse between continents. These results suggest that the underlying process is best explained by a non-neutral, competition-driven model.

\section{Results}

\subsection{Diversity accumulation}

We found a nearly continuous increase in diversity across the entire carnivore phylogeny, both globally and within continents, for both phylogenetic and taxonomic diversity (Fig. 1). There were only three main exceptions: 1) Diversity in North America initially peaked at the early Eocene climatic optimum and then decreased in the interval 50 to 45 million years ago (Ma). Given that the majority of species at that time were confined to this continent, a similar decrease was also seen in global 
111

112

113

114

115

diversity. 2) Diversity in both North America and Eurasia decreased over the last 10 My. 3) There was a decline in phylogenetic (but not species) diversity in Eurasia between approximately 40 to 35 Ma. Similar results were obtained independently of the length of the time bins being analysed and showed only limited variation across the 100 trees (Fig. 2).

These results were based on the assumption of complete sampling. However, the increase in diversity through time could be partially caused by an increase in sampling intensity towards the present. We showed through simulations that this is very unlikely. Our simulations showed very limited effects of incomplete sampling on the observed patterns when using empirically derived sampling intensities (Figure S1).

\subsection{Higher evolutionary success of dispersers}

We estimated the evolutionary success of dispersers using two novel metrics, which we refer to as predispersal success and post-dispersal success (Fig. 3). Pre-dispersal success measures the diversification rate of lineages at the time of their dispersal, whereas post-dispersal success measures how many species the dispersing lineages diversify into.

\subsubsection{Pre-dispersal success}

Our analyses of pre-dispersal success suggest that the dispersing species belong to clades that, at the time of dispersal, were diversifying faster than non-dispersers (Tables 1, S1-S2). This pattern was observed irrespective of whether comparisons were to all species alive in the time interval, or only to species occurring on the source continents in the time interval (which we refer to as global and continental pre-dispersal success). We estimated dispersal within time bins rather than in continuous time, but the results were independent of the length of these bins. The best model for continental predispersal success showed a difference in success between dispersers and non-dispersers depending on the target continent. In particular, the model showed a substantially smaller difference between dispersers and non-dispersers for species colonizing South America. The best model for global predispersal success showed temporal variation, where the difference in success between dispersing and remaining lineages was smaller for older dispersal events. In both cases, however, both models had 
lower AIC than the model without any spatial or temporal variation. Thus, the two analyses only disagreed on whether spatial or temporal variation was most important.

Our analyses assumed complete sampling of all extinct species but we tested the consequences of this assumption through simulations. For this, we modelled scenarios of no difference in diversification patterns between dispersers and non-dispersers and assessed if spatial patterns in sampling would create a false signal with such a difference. These simulations showed that the patterns of pre-dispersal success were not caused by incomplete sampling (Table S3-S4). The simulations of global pre-dispersal success found no significant difference in success between dispersers and non-dispersers and found no support for any spatial or temporal variation in the difference between dispersers and non-dispersers. The simulations of continental pre-dispersal success also found no significant difference in success between dispersers and non-dispersers. They did, however, recover weak support based on AIC for models with temporal, but not spatial, variation in the difference between dispersers and non-dispersers. Even then, the estimated effect size for temporal variation was not significantly different from zero. If sampling effort did have an effect on spatial or temporal variation in our results, the effect size must have been minimal.

\subsubsection{Post-dispersal success}

Our results clearly demonstrate that dispersing lineages leave more descendant lineages than lineages that remain within the source continents (Table 2). This applies to both continental and global postdispersal success (i.e. comparisons to all other species on the target continent or all species alive at the time of dispersal). This pattern - that dispersers leave more descendant lineages - remained constant irrespective of the length of the analysed time bin and how long after the dispersal the number of descendant species was counted (Tables S5-S6). The model with spatial variation was, however, only supported for continental (but not global) post-dispersal success and similar, although weaker, support for spatial variation was also recovered when we simulated incomplete sampling (Table S7). We, therefore, focus our discussion solely on the strong evidence for higher post-dispersal success rather than on any more detailed spatial or temporal patterns regarding the magnitude of this success. 


\section{Discussion}

Our results unequivocally show a positive correlation between diversification rate and dispersal in carnivores. The analyses are based on the first species-level phylogeny of carnivores that includes all suitable fossils and all extant species. These results contradict an expected neutral pattern of a tradeoff between diversification rate and dispersal, as has been suggested based on analyses of contemporary mammals (6).

\subsection{Diversity accumulation}

The occasional periods of diversity decline detected by our analyses lend biological credence to our results, since a monotonous increase in diversity could point towards a pattern driven by insufficient fossil information. All three declines detected clearly match previous knowledge. The first two declines were likely climatically driven. If carnivores throughout their history have had lower diversity in higher latitudes, similar to what we see today (21), we should expect to see diversity declines during times of global temperature decline, particularly in North America and Eurasia, which have the highest proportions of non-tropical areas. In this regard, the first early decline in North America coincides with a period of Eocene cooling (22) and is temporally similar to a time period recently found to have a low overall mammalian diversity in North America (23). Secondly, the declines in North America and Eurasia during the last 10 My may be explained by the overall climatic cooling during this time period (24).

In contrast, the third decline in phylogenetic diversity in Eurasia may not have been climatically driven. Instead, it probably reflects the so-called 'Grande Coupure', where the formerly isolated European fauna was replaced by an immigrant Asian fauna (e.g. 25). The cause of the Grande Coupure is not entirely known (25) but if it represents biotic replacement driven by competition, which is one of the hypotheses (25), it may indicate that such processes are important for carnivores in general.

\subsection{Neutral or non-neutral models}


Our results for pre-dispersal success and post-dispersal success clearly suggest that dispersal rate and among good dispersers is only expected under the non-neutral models. would be expected to be lower. This matches the expectations of this model - the non-neutral model would only generate a relationship between pre-dispersal success for dispersers and non-dispersers if dispersal to other continents required the displacement of lineages already there. There should be smaller differences if there are free niches open to any coloniser. This non-neutral model, therefore, contrasts with the frequently found priority effects in community ecology where the first coloniser is nearly always more successful (26).

America, which matches our expectations. Under non-neutral models, we only expect elevated predispersal success for dispersers if these are invading already occupied niches. The South American continent lacked placental carnivores until the mid-Miocene (27), and all invading carnivores would have initially encountered empty ecological niches. The pattern of elevated pre-dispersal success in North America is expected because our analyses suggest that carnivores originated in North America. Our results also show that the clade has consistently been highly diverse in that continent (Fig. 1). This North American origin is clear from Oxyaenidae, which is one of the three earliest diverging clades we analyze (28). The origin of the two other clades (Carnivoramorpha and Hyaenodonta) has previously been considered to be Eurasian or African, but even studies suggesting a non-North American origin for these clades have suggested extremely rapid dispersal to, and substantial diversification within, North America $(29,30)$. 
223 (Tables 1-2). The reason for this difference may partly be a function of the non-phylogenetic approach

of Pires et al (31), meaning that the different outcomes of multiple dispersals within the same family could not be distinguished.

As a minor point of uncertainty, we note that we treat the carnivore niche in South

America as unoccupied, although it was occupied prior to the arrival of the placental carnivores by the Sparassodonta (Metatheria; sister group to marsupials). It is still unknown if the Sparassodonta went extinct independently of the arrival of placental carnivores, or if they were driven to extinction by competitive replacement (32). Non-placental lineages seem, however, to be inherently inferior competitors to placental carnivores, likely due to effects related to their lack of deciduous teeth (33, 34, 35). It, therefore, seems plausible that if the Sparassodonta were still extant when the carnivores arrived then any member of the group that arrived there may have been able to outcompete them.

\subsection{Implications}

Our results suggest a model of consistent competitive replacement among carnivore clades, although the generality of the observed pattern remains unclear. The methodology we employed was possible because carnivores have a well-understood fossil history, which is why the effects of incomplete sampling were deemed minor (Tables S3-S4, S7; Fig. S1). Furthermore, carnivores are a particularly useful group to study for this purpose because there is strong phylogenetic conservatism in their niche, with few other taxa competing with them. They are thus nearly a monophyletic ecological guild, although there are exceptions to this; some species within the group, such as the giant and red pandas, for instance, are predominantly herbivorous (3). Until the Eocene, carnivores shared the carnivorous niche with other mammalian species of uncertain placement, such as Arctocyonidae or Cimolestidae (36), but even then, carnivores plausibly comprised the majority of the guild (12). Arguably, the only other large monophyletic mammalian group that behaves like an ecological guild is bats, but they are noteworthy for having a particularly scarce fossil record among mammals (37). It may therefore not be possible at present to directly replicate our analyses using other clades and thereby directly test the generality of the patterns reported here. 
that the patterns we report here would be taxon-specific. Taxon specificity could have explained why our results appear to run counter to some studies showing lower diversification rates for species with higher dispersal rates $(6,7)$. We think, however, that the apparent differences are instead a consequence of the taxonomic scale of the analyses and the inclusion or exclusion of fossil taxa. A lower diversification rate in highly dispersing lineages has been recovered in analyses at the subfamily or family level, whereas our estimates here are conducted at the species level. Direct competition may be strongest between the most closely related species in the case of mammals (38), which is also what would be expected for any traits with phylogenetic conservatism. This would explain the apparent conflict between this and earlier analyses of mammals. Earlier analyses at the subfamily level have suggested a negative relationship between dispersal and diversification rate in mammals (6), whereas in a species-level analysis we here recover a positive relationship between the two. is increasingly being acknowledged (39). However, competition may be expected to be linked to physiological or morphological traits, which are generally more similar for closely related species.

There are many examples of convergent evolution within mammals (e.g. 40, 41), but even so, recently diverged species will be more similar than a random pair of species under most evolutionary models.

They must, therefore, be expected to rely more on the same resources and the same environmental conditions than random members of a larger clade. observable because we included fossil species in our analyses. When species are driven to extinction by other species it may be on too fast a time scale for us to see it clearly based only on extant species in their native ranges. The only clear contemporary evidence for biologically caused extinctions or declines comes from the invasion biology literature (e.g. 42). Competition-driven extinctions could leave signals on the phylogenies of the extant species but, as we noted in the introduction, such

275 declines may be extremely difficult to detect based on phylogenies of extant species only $(15,16,17)$.

276 Even in the few situations where declines can be detected, methods solely relying on contemporary

277 species can logically only give a signal if the declining lineages still have at least one extant species. 
278 Some of the clearest cases of clade competition, such as the bone-crushing dogs (Borophaginae) being

279 driven to extinction by related and extant modern dogs (Caninae) (13), are thus impossible to infer

280 without fossils.

In summary, our analysis of a novel species-level phylogeny of all extant and extinct

carnivores shows that: 1) lineages that disperse between continents are generally those that diversify

more quickly; and 2) lineages that colonise new continents leave more descendant species than

lineages already present there. These results are only likely to have emerged because we combined

fossil and phylogenetic information, highlighting the need to incorporate both sources of information

whenever possible.

\section{Methods}

\subsection{Method summary}

290 We analysed all extant and extinct species of mammalian carnivores and related extinct groups

291 (Carnivoramorpha, Hyaenodonta, and Oxyaenidae). Herein we refer to this entire clade as

'carnivores'. We revisited the taxonomy of all fossil and extant members of the group and accepted,

1723 species (314 of which are extant). We based our analyses on records in the Paleobiology

Database (PBDB; https://paleobiodb.org/) and the New and Old Worlds Database of fossil mammals

literature for 128 species that we consider valid but which, at least when we were collecting data, lacked any records in either of the two databases. dating approach under a fossilised birth-death model in MrBayes 3.2 (43). We did this in a two-step procedure combining a backbone tree with a number of smaller phylogenies at lower taxonomic levels. This procedure is similar to that used to construct phylogenies focusing on other large clades (e.g. 44, 45), but it has previously only been used to generate all-taxon phylogenies of all extant species within a clade. This is the first time it has been expanded to include all extant and extinct species within the focal clade. The placement of species without genetic or morphological data was facilitated by a number of constraints based on taxonomy and suggested relationships from taxonomic treatments. 

extinction times generated by the Bayesian program PyRate (46), which estimated likely extinction times based on the temporal distribution of all known records of each species. The resulting phylogeny is attached as appendix 1 giving 1000 trees from the posterior distribution of trees We included pinnipeds to improve the usability of the phylogeny for other researchers, but here we discarded them for all analyses for this paper due to our focus on terrestrial species.

$\mathrm{DEC}+\mathrm{j}$ model since the underlying mathematical properties of the $\mathrm{DEC}+\mathrm{j}$ model have been questioned (48). Following the estimation of ancestral areas for all nodes, we inferred dispersal events and times along branches. phylogenetic diversity (49) (i.e. the sum of branch lengths). Following this, we analysed the evolutionary success (estimated as their diversification rate) of dispersers at the time of their dispersal (pre-dispersal success) and the number of descendant species they left behind after a set time (postdispersal success). meaningfully interpretable for ultrametric trees. For simplicity, extinction was therefore dealt with in time intervals rather than in continuous time and on trees sliced at various ages, only counting the species (internal or external branches) extant at that point in time. Hence, when using 0.5 My time intervals, two species that went extinct 1.2 and 1.4 Ma were assumed to have survived until 1.0 Ma and would both be included as extant for a tree sliced at 1.0 Ma. To test the effect of this procedure on the results, all analyses were conducted with time intervals of $0.25,0.5$ or $1.0 \mathrm{My}$ duration. the tree at the end of each time interval throughout the Cenozoic and calculated the DR of all lineages alive at that time. For all intercontinental dispersal events occurring in the following time interval, we then identified the lineage at the beginning of the interval that would evolve into the disperser during the interval. This could be either the same species or one of its ancestors, which would be the case for 
334 founder speciation occurring within the time interval. We then calculated the logarithm of the ratio

335 between the diversification rate of the disperser and the median diversification rate for either all

336 lineages alive in the time interval (global pre-dispersal success) or the subset of these that was found

337 on the same continent the disperser originated in (continental pre-dispersal success). This calculation

338 is outlined in Fig. 3.

We estimated post-dispersal success by comparing the tree at the time before dispersal with the tree sliced a number of million years afterwards. For each lineage alive at the first time interval, we identified how many species it had diversified into a few million years later (which was 0 if the lineage had gone extinct in the meantime). We then calculated the ratio between the number of species in the dispersing lineage and the mean for either all other species (global post-dispersal success) or all species from the continent dispersed to (continental post-dispersal success). In both cases, we square-root-transformed the post-dispersal success to improve normality. Separate analyses of post-dispersal success were conducted on trees sliced after 3, 5, and $7 \mathrm{My}$. may be missing from the fossil record, which may influence our results, especially since the fraction of missing species is likely to vary in time and space. In order to understand the influence of missing taxa on our results, we, therefore, simulated a number of random phylogenies. We then simulated incomplete sampling on those phylogenies based on spatial and temporal sampling effort estimated in the PyRate analyses described above. Following this, we repeated all analyses described above on both the full and the sampled phylogenies in order to directly measure the effect of incomplete sampling on our results. methods. jawed vertebrates. Proc. Natl Acad. Sci. USA 106, 13410-13414 (2009) 
2) Sepkoski, J. A factor analytic description of the Phanerozoic marine fossil record. Paleobiology 7, 36-53 (1981.

3) Faurby, S. et al. PHYLACINE 1.2: The phylogenetic atlas of mammal macroecology Ecology 99, 2626 (2018) (2017)

6) Faurby. S. \& Antonelli, A. Evolutionary and ecological success is decoupled in mammals. $J$. Biogeogr. 45, 2227-2237 (2018)

7) Weeks, B. C. \& Claramunt, S. Dispersal has inhibited avian diversification in Australasian archipelagos. Proc. R. Soc. B 281, 20141257 (2014)

8) Quantal, T. B. \& Marshall, C. R. How the Red Queen drives terrestrial mammals to extinction. Science 341, 290-292 (2013)

9) Žliobaitè, I., Fortelius, M. \& Stenseth, N. C. Reconciling taxon senescence with the Red Queen's hypothesis. Nature 552, 92-95 (2017)

10) Worthy, T. H. et al. Miocene mammal reveals a Mesozoic ghost lineage on insular New Zealand, southwest Pacific. Proc. Natl Acad. Sci. USA 103, 19419-19423 (2006)

11) Upham, N., Esselstyn, J. A. \& Jetz, W. Ecological causes of uneven diversification and richness in the mammal tree of life. bioRxiv https://doi.org/10.1101/504803 (2019)

12) Valkenburgh, B. V. Major patterns in the history of carnivorous mammals. Annu. Rev. Earth Planet. Sci 27, 463-493 (1999)

13) Silvestro, D., Antonelli, A., Salamin, N. \& Quental, T. B. The role of clade competition in the diversification of North American canids. Proc. Natl Acad. Sci. USA 112, 8684-8689 (2015)

14) Cantalapiedra, J. L., Prado, J. L., Hernández Fernández, M. \& Alberdi, M. T. Decoupled ecomorphological evolution and diversification in Neogene-Quaternary horses. Science 355, $627-630(2017)$ 
15) Quantal, T. B. \& Marshall, C. R. The molecular phylogenetic signature of clades in decline. PLoS One 6, e25780 (2011)

16) Rabosky, D. L. Extinction rate should not be estimated from molecular phylogenies. Evolution 64, 1816-1824 (2010)

17) Louca, S. \& Pennell, M. W. Phylogenies of extant species are consistent with an infinite array of diversification histories. bioRxiv doi.org/10.1101/719435 (2019)

18) Silvestro, D., Schnitzler, J., Liow, L. H., Antonelli, A. \& Salamin, N. Bayesian estimation of speciation and extinction from incomplete fossil occurrence data. Syst. Biol. 63, 349-367 (2014)

19) Fritz, S.A. et al. Diversity in time and space: wanted dead and alive. Trends Ecol. Evol. 28, 509-516 (2013)

20) Slater, G. J. \& Harmon, L. J. Unifying fossils and phylogenies for comparative analyses of diversification and trait evolution. Methods Ecol. Evol. 4, 699-702 (2013)

21) Sandom, C. et al. Mammal predator and prey species richness are strongly linked at macroscales. Ecology 94, 1112-1122 (2013)

22) Bohaty, S. M. \& Zachos, J. C. Significant Southern Ocean warming event in the late middle Eocene. Geology 31, 1017-1020 (2003)

23) Brodie, J. F. Environmental limits to mammal diversity vary with latitude and global temperature. Ecol. Lett. 22, 480-485 (2019)

24) Zachos, J., Pagani, M., Sloan, L., Thomas, E. \& Billups, K. Trends, rhythms and aberrations in global climate 65 Ma to present. Science 292, 686-693 (2001)

25) Costa, E., Garces, M., Saez, A., Babrera, L. \& López-Blanco, M. The age of the “Grande Coupure" mammal turnover: New constraints from the Eocene-Oligocene record of the Eastern Ebro Basin (NE Spain). Palaeogeography, Palaeoclimatology, Palaeoecology 301, 97-107 (2011)

26) Fukami, T. Historical contingency in community assembly: Integrating niches, species pools, and priority effects. Annu. Rev. Ecol. Evol. Syst. 46, 1-23 (2015) 
27) Webb, S.D. The great American biotic interchange: patterns and processes. Ann. Missouri Bot. Gard. 93, 245-275. (2006)

28) Chester, S. G. B., Bloch, J. I., Secord, R. \& Boyer, D. M. A new small-bodied species of Palaeonictis (Creodonta, Oxyaenidae) from the Paleocene Eocene thermal maximum. $J$. Mamm. Evol. 17, 227-243 (2010)

29) Borths, M. R., Holroy, P. A. \& Seiffert, E. R. Hyainailourine and teratodontine cranial material from the late Eocene of Egypt and the application of parsimony and Bayesian methods to the phylogeny and biogeography of Hyaenodonta (Placentalia, Mammalia). PeerJ 4, e2639 (2016)

30) Solé, F., Smith, T., De Bast, E., Codrea, V. \& Gheerbrant, E. New carnivoraforms from the latest Paleocene of Europe and their bearing on the origin and radiation of Carnivoraformes Carnivoramorpha, Mammalia). J. Vert. Paleontol. 36, e1082480 (2016)

31) Pires, M. M., Silvestro, D. \& Quental, T. B. Continental faunal exchange and the asymmetrical radiation of carnivores. Proc. R. Soc. B 282, 20151952 (2015)

32) Prevosti, F. J., Forasiepi, A. \& Zimicz, N. The Evolution of the Cenozoic Terrestrial Mammalian Predator Guild in South America: Competition or Replacement? J. Mamm. Evol. 20, 3-21 (2013)

33) Werdelin, L. Jaw geometry and molar morphology in marsupial carnivores: analysis of a constraint and its macroevolutionary consequences. Paleobiology 13, 342- 350 (1987)

34) Croft, D.A. Do marsupials make good predators? Insights from predator-prey diversity ratios. Evol. Ecol. Res. 8, 1193-1214 (2006)

35) Faurby, S. \& Svenning, J. C. The asymmetry in the Great American Biotic Interchange in mammals is consistent with differential susceptibility to mammalian predation. Glob. Ecol. Biogeogr. 25, 1443-1453 (2016)

36) Halliday, T. J. D., Upchurch, P. \& Goswami, A. Resolving the relationships of Paleocene placental mammals. Biol. Rev. 92, $521-550$ (2015)

37) Barnosky, A. D. et al. Has the Earth's sixth mass extinction already arrived? Nature 471, 5157 (2011) 
38) Cooper, N., Rodríguez, J. \& Purvis, A. A common tendency for phylogenetic overdispersion in mammalian assemblages. Proc. R. Soc. B 275, 2031-2037 (2008)

39) Wilcox, T. M., Schwartz, M. K. \& Lowe, W. H. Evolutionary community ecology: Time to think outside the (taxonomic) box. Tr. Ecol. Evol. 33, 240-250 (2018)

40) Chikina, M., Robinson, J. D. \& Clark, N. L. Hundreds of genes experienced convergent shifts in selective pressure in marine mammals. Mol. Biol. Evol. 33, 2182-2192 (2016)

41) Mazel, F. et al. The geography of ecological niche evolution in mammals. Curr. Biol. 27, $1369-1374(2017)$

42) Burbidge, A. A. \& Manly, B. F. J. Mammal extinctions on Australian islands: causes and conservation implications. J. Biogeogr. 29, 465-473 (2002)

43) Ronquist, F. et al. MrBayes 3.2: efficient Bayesian phylogenetic inference and model choice across a large model space. Syst. Biol. 61, 539-542 (2012)

44) Faurby, S., Svenning, J. C. A species-level phylogeny for all extant and Late Quaternary extinct mammals using a novel hierarchical Bayesian approach that accounts for topological uncertainty. Mol. Phylogenetics Evol. 84, 14-26 (2015)

45) Jetz, W., Thomas, G. H., Joy, J. B., Hartmann, J. K. \& Mooers, A. O. The global diversity of birds in space and time. Nature 491, 444-448 (2012)

46) Silvestro, D., Salamin, N. \& Schnitzler, J. PyRate: a new program to estimate speciation and extinction rates from incomplete fossil data. Methods Ecol. Evol. 5, 1126-1131 (2014)

47) Matzke, N. J. BioGeography with Bayesian (and Likelihood) evolutionary analysis in R scripts. Retrieved from https://cran.rproject.org/web/packages/BioGeoBEARS/BioGeoBEARS.pdf (2013).

48) Ree, R. H. \& Sanmartin, I. Conceptual and statistical problems with the DEC+J model of founder-event speciation and its comparison with DEC via model selection. J Biogeogr $\mathbf{4 5}$, $741-749(2018)$

49) Faith, D. P. Conservation evaluation and phylogenetic diversity. Biol. Conserv. 284, 1-10. (1992) 
472 Supplementary Materials:

473 Supplementary materials and methods

474 Tables S1-S9.

475 Figures S1-S2.

476 Appendix 1: The produced phylogeny of all carnivores

477 Appendix 2. A description of our treatment of all the individual fossil records

478

479 Acknowledgments: Funding: Funding for this work was provided through a Wallenberg Academy

480 Fellowship from the Knut and Alice Wallenberg Foundation, by the Swedish Research Council

481 (B0569601, 2015-04587, and 2017-03862), the Swedish Foundation for Strategic Research and the

482 Royal Botanic Gardens, Kew. Author contributions: SF, LW, and AA designed the study. SF and LW

483 performed the taxonomic cleaning for all records. SF conducted all analyses. SF led the writing of the

484 paper with input from LW and AA. All authors approved the submitted version. Competing interests:

485 Authors declare no competing interests. Data and materials availability: The produced phylogeny is

486 added as an appendix. All scripts used for running individual analyses are available from the authors

487 upon request.

488 
Table 1: Pre-dispersal success.

Pre-dispersal success was estimated as the logarithm of the ratio between the diversification rate of the dispersing lineage dispersers and the median of the dispersal rates of the remaining species alive at the time of dispersal (see Fig. 3). Separate analyses were conducted comparing the dispersers with either all species alive (global pre-dispersal success) or only the species alive in the source continent (continental pre-dispersal success).

The p-values for node age and for global rate are the probability of the estimate in question being greater than 0 . For models with different patterns depending on continental source and target, the pvalue is based on the probability of being different from the estimated global rate.

This table only lists the results for the simplest model, and models preferred by AIC for either global or continental pre-dispersal success. The results from the remaining models are provided in the supplementary material (Tables S1-S2). Values are only given for time intervals of 0.5 million years, but results are similar for the other two intervals (Tables S1-S2).

\begin{tabular}{lll}
\hline & Continental pre-dispersal success & Global pre-dispersal success \\
\hline \multicolumn{1}{c}{ Simplest model } \\
\hline Global & \multicolumn{1}{c}{$0.0835(0.0194)^{* * * *}$} & $0.1205(0.0205)^{* * *}$ \\
$\Delta$ AIC & \multicolumn{1}{c}{ Temporal variation } \\
\hline \multicolumn{1}{c}{0.178} \\
\hline Global & $0.1122(0.0259)^{* * *}$ & $0.1636(0.0272)^{* * *}$ \\
Age before present & $-0.0018(0.0012)^{\circ}$ & $-0.0027(0.0013)^{*}$ \\
$\Delta$ AIC & 4.079 & 0.000 \\
\hline \multicolumn{2}{c}{ Variation between target continent } \\
\hline To Africa & $0.1160(0.0373)$ & $0.1468(0.0372)$ \\
To Eurasia & $0.0453(0.0343)$ & $0.1050(0.0362)$ \\
To North America & $0.1260(0.0360)$ & $0.1420(0.0370)$ \\
To South America & $0.0017(0.0503)$ & $0.0423(0.0528)$ \\
$\Delta$ AIC & 0.000 & 5.873 \\
\hline${ }^{\circ} 0.10>\mathrm{P}>0.05 * 0.05>\mathrm{P}>0.01 * * 0.01>\mathrm{P}>0.001 * * * 0.001>\mathrm{P}$ \\
\hline
\end{tabular}




\begin{tabular}{|c|c|c|}
\hline \multicolumn{3}{|c|}{$\begin{array}{l}\text { Table 2: Post.dispersal success. } \\
\text { Post-dispersal success is estimated as the square root of the ratio between the number of } \\
\text { descendants for each dispersing lineage alive } 5 \text { million years (My) after dispersal divided by the } \\
\text { mean number of descendants for any species alive at the time of dispersal (see Fig. 3). Separate } \\
\text { analyses were conducted comparing the dispersers with either all species alive then (global post- } \\
\text { dispersal success) or only the species alive in the target continent (continental post-dispersal } \\
\text { success). P-values for node age and for global rate are the probability of the estimate in question } \\
\text { being higher than } 1 \text { (the null expectation). For models with different patterns depending on } \\
\text { continental source and target, the p-value is based on the probability of being different from the } \\
\text { estimated global rate. } \\
\text { Values are only given for time intervals of } 0.5 \mathrm{My} \text { and only based on the number of species alive } \\
\text { after } 5 \mathrm{My} \text {, but results are similar for time intervals of } 0.25 \text { and } 1.00 \text { and after } 3 \text { or } 7 \mathrm{My} \text { (Tables } \\
\text { S5-S6). This table only lists the results for the simplest model, and models preferred by AIC for } \\
\text { either global or continental post-dispersal success. The results from the remaining models are } \\
\text { provided as supplementary material (Tables S5-S6). }\end{array}$} \\
\hline & Continental post-dispersal success & Global post-dispersal success \\
\hline \multicolumn{3}{|c|}{ Simplest model } \\
\hline Global & $1.4433(0.0730)^{* * * 3 *}$ & $1.4606(0.0730)^{* * * *}$ \\
\hline$\triangle \mathrm{AIC}$ & 5.792 & 0.000 \\
\hline \multicolumn{3}{|c|}{ Variation between source and target continent } \\
\hline Africa to Eurasia & $1.2666(0.1727)$ & $1.3557(0.1777)$ \\
\hline Eurasia to Africa & $1.3607(0.1206)$ & $1.3991(0.1184)$ \\
\hline Eurasia to North America & $1.6677(0.1282)^{\circ}$ & $1.5767(0.1243)$ \\
\hline North America to Eurasia & $1.4238(0.1487)$ & $1.4572(0.1428)$ \\
\hline North to South America & $1.1263(0.2925)$ & $1.4005(0.2835)$ \\
\hline & 0.000 & 1.685 \\
\hline
\end{tabular}

Figure 1: Temporal changes in diversity.

Change in species and phylogenetic diversity through time globally (in black) and separately per continent (different colours). Lines represent median values across 100 trees for 0.5 -million-year time intervals. The variation between trees and between lengths of the study interval can be seen in Fig. 2 .
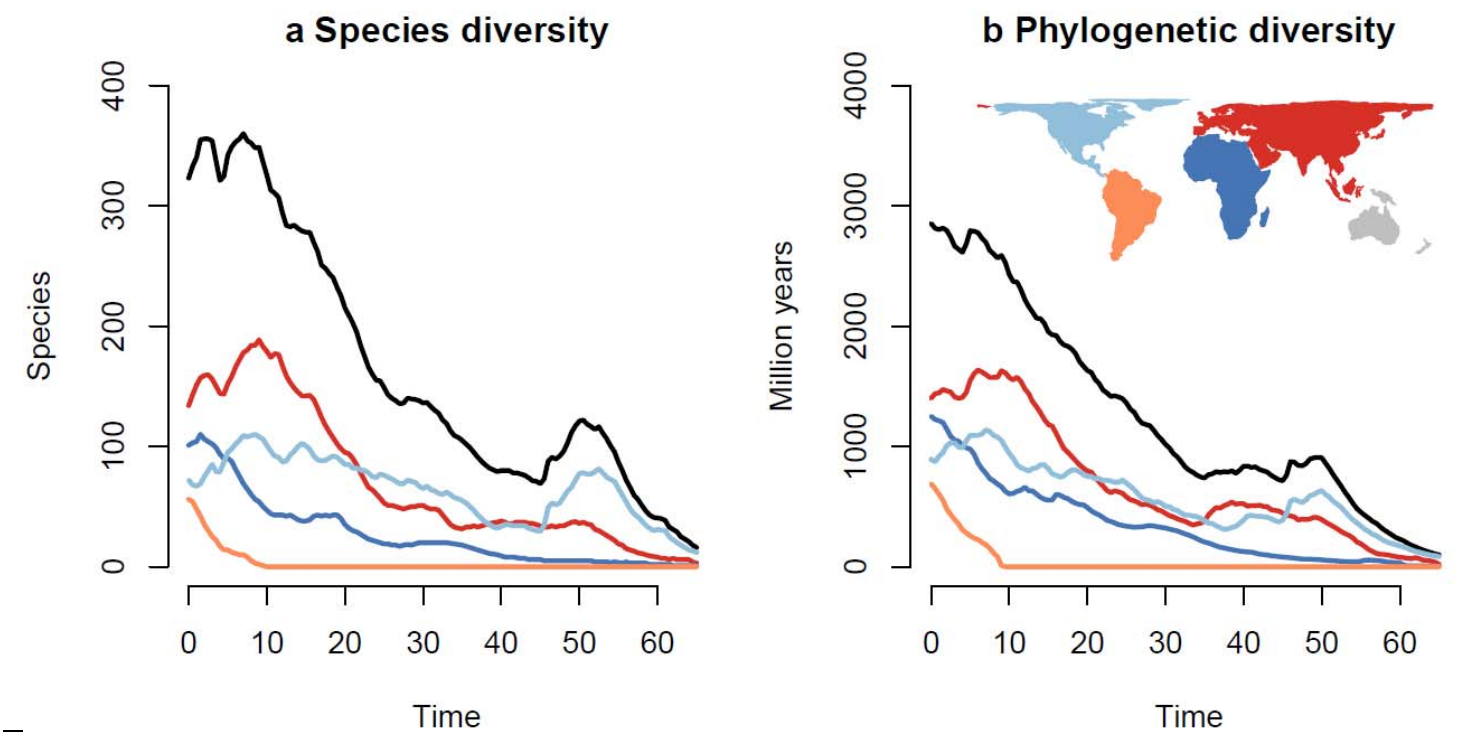

Figure 2: Variation in diversification rate among trees. 
Plots of diversity through time for 100 trees drawn from the Bayesian phylogenetic analysis. Results for each tree are drawn as separate lines with results for different sample periods shown in different colours. Due to the strong consistency of results between trees and between lengths of the intervals many lines are drawn on top of each other.
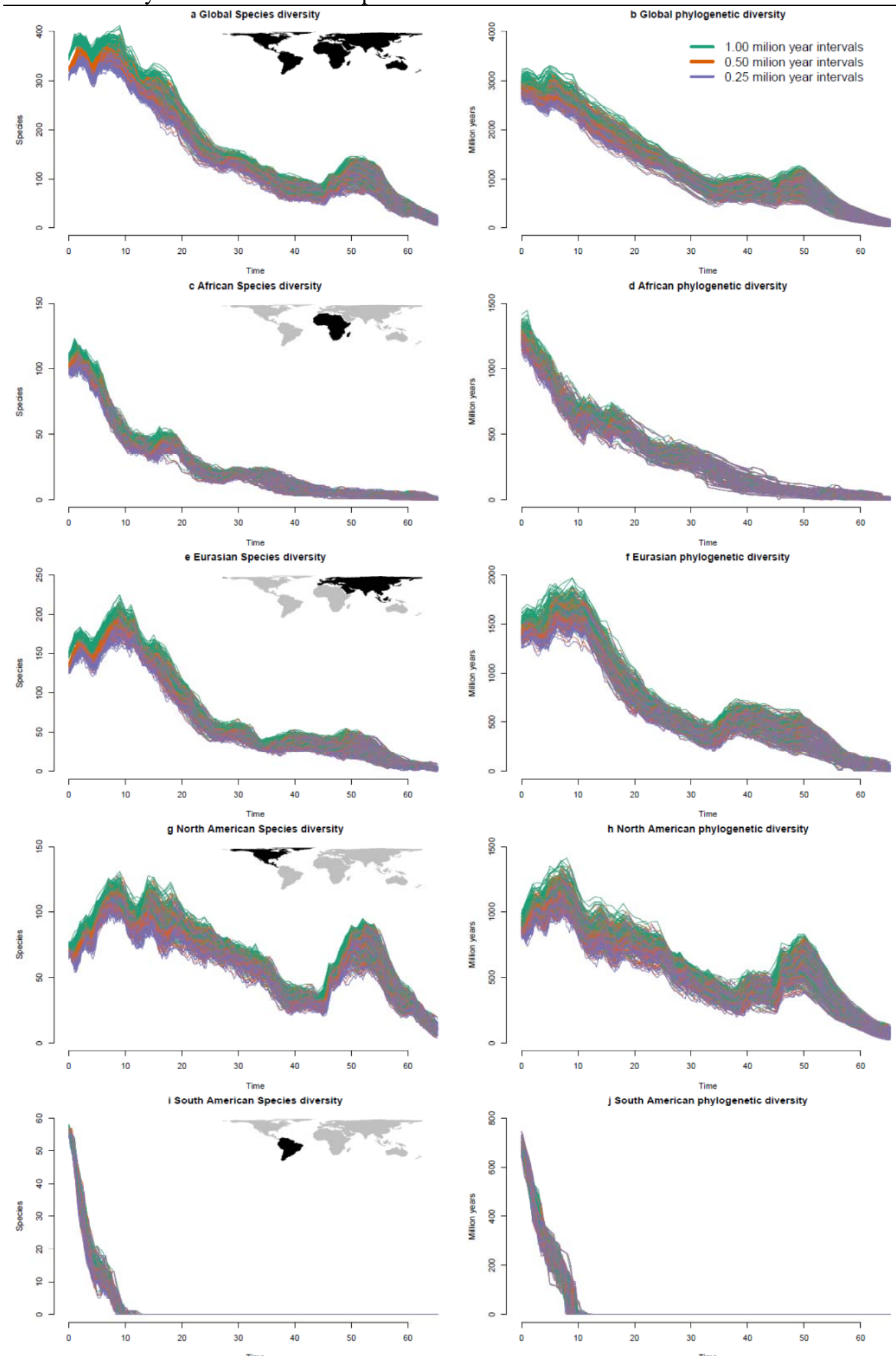
Figure 3: Estimation of dispersal success.

Pre-dispersal success

Post-dispersal success

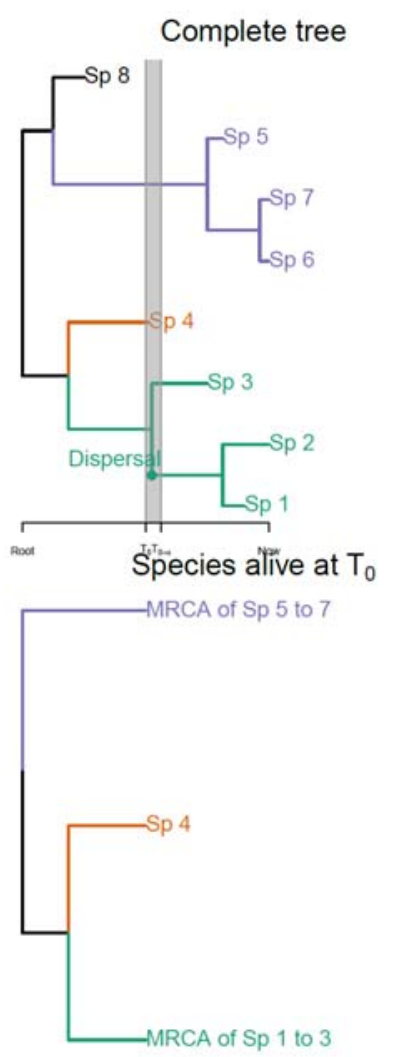

Diversification rates

$D_{\text {MRCA of } S p 1 \text { to } 3}=0.250$

$\mathrm{DR}_{\mathrm{Sp} 4}=0.308$

$\mathrm{DR}_{\mathrm{Sp} 567}=0.308$
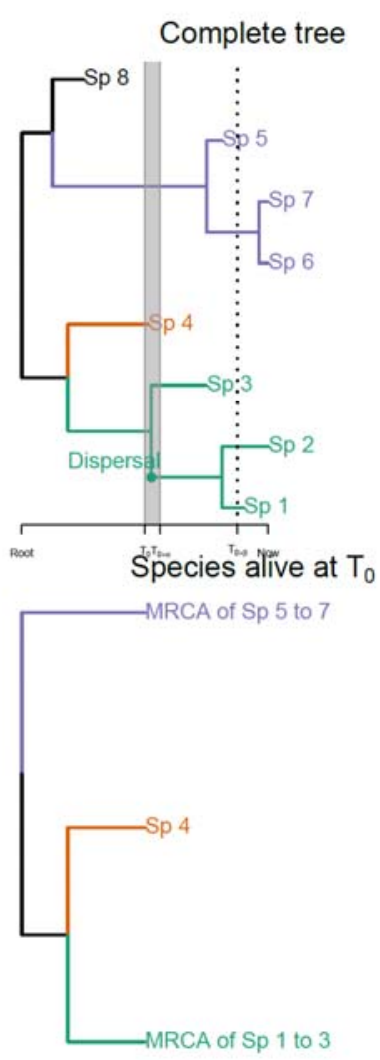

Species alive at $\mathrm{T}_{0+\beta}$ -MRCA of Sp 6 and 7

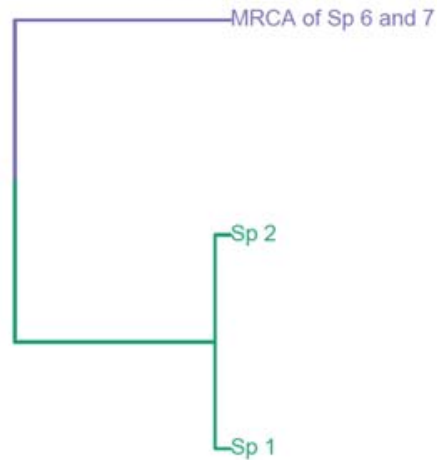

Calculation

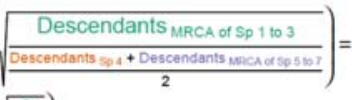

$\left.\sqrt{\frac{2}{\frac{0+1}{2}}}\right)=2$

In the example above, one dispersal event happened within the interval from $\mathrm{T}_{0}$ and $\mathrm{T}_{0+\alpha}$. where $\alpha$ represents the time interval, which in our case was $0.25,0.5$ or 1.0 million years (My). 


\section{Both Pre-dispersal success and Post-dispersal success are calculated on the same tree.}

The panels on the right illustrate how Pre-dispersal success is calculated. In order to improve understanding, we have used the same colours on each panel to show corresponding parts of trees or equations.

The two first panels show the entire tree, and a tree of just the species alive at time $\mathrm{T}_{0}$. The third panel shows DR rates estimated as in (44) for the species alive at $\mathrm{T}_{0}$. The fourth shows the calculation of Pre-dispersal success, which we define as the logarithm to the ratio between the DR of the dispersing lineage and the median of the remaining lineages (see the methods section for details).

The panels on the left illustrate how Post-dispersal success is calculated. In order to improve understanding, we have used the same colours on each panel to show corresponding parts of trees or equations.

The first panel shows the entire tree. This is identical to the tree for Pre-dispersal success except that a stippled line has been added at time $T_{0+\beta} . \beta$ here represents a pre-defined length of time (in our case 3,5 or $7 \mathrm{My}$ ). Post-dispersal success compared the trees at $\mathrm{T}_{0}$ and $\mathrm{T}_{0+\beta}$ and how many descendant species, each species alive at $\mathrm{T}_{0}$ has diversified into. The next two panels show the trees of the species alive at $\mathrm{T}_{0}$ and $\mathrm{T}_{0+\beta}$ respectively. The last panel illustrates the calculation of Postdispersal success, which we defined as the square root of the ratio between the number of descendants of the dispersing lineage and the mean number of descendants for any lineage from time $\mathrm{T}_{0}$ alive at time $\mathrm{T}_{0+\beta}$. Note that we here only look at the descendants alive at this time point and not all descendants. This, for instance, means that the taxon "MRCA of Sp 5 to 7" has only diversified into one species at time $\mathrm{T}_{0+\beta}$ ("MRCA of Sp 6 and 7") ) because Sp 5 is already extinct by then and the split between Sp 6 and Sp 7 happens at a later stage (see the methods section for details). 


\section{Supplementary materials}

497

\section{$498 \quad 5$ Supplementary materials and methods}

\subsection{Phylogeny}

500

501

502

503

504

505

506

507

508

509

510

511

512

513

514

515

516

517

518

519

520

521

522

523

\subsubsection{Input data}

We downloaded all records of carnivores identified at least to genus level from the Paleobiology

Database (PBDB; https://paleobiodb.org/) on October 10, 2016 and the New and Old Worlds Database of fossil mammals New and Old Worlds Database of fossil mammals (http://www.helsinki.fi/science/now/; NOW), on September 30, 2016. We defined the focal clade as Carnivoramorpha (Carnivora and Miacoidea) + Creodonta (Hyaenodonta and Oxyaenidae). Hereafter, we refer to this entire clade as 'carnivores' and use the term 'Carnivora' when referring exclusively to the extant order.

We revisited the taxonomy of all named species to generate a consistent list matching current knowledge of extinct mammals, as well as the taxonomy of species surviving at least until the Late Pleistocene (hereafter 'extant carnivores'). For the latter, we followed the taxonomy of the Phylacine V 1.2 database (3). Phylacine follows the International Union for Conservation of Nature (IUCN) version 2016-3 for extant species and extinct species with extinction dates post $1500 \mathrm{AD}$, and an updated version of the database of Faurby and Svenning (44) for species that went extinct between the Late Pleistocene and 1500 AD. The resulting dataset had 7,551 useable records from NOW (6,285 records assigned to a species and 1,266 only to genus, while 94 records from the database were not assignable to any of the genera we accept and were therefore excluded) and 7,984 useable records from PBDB (6,755 records assigned to species and 1,229 only to genus, while 123 were not assignable to any of our genera and therefore excluded).

Our combined dataset consisted of 1,723 species after cleaning, 314 of which are extant. Among the species that went extinct prior to the Late Pleistocene, 631 were included in both NOW and PBDB, 382 only had records in the NOW Database, and 268 only had records in PBDB. An additional 128 species were manually added since they were not included in either of the databases at the time of original download (October 10, 2016, and September 30, 2016 for the PBDB and NOW 
524 databases, respectively; see Table S8). We included a few forms as separate species entities although

525 not formally described as such. Five genera had records only identified at the genus level from North

526 America. For our analyses, we treat these as distinct species, such as "Parailurus NorthAmerica".

527 Although species designation for these has not formally been made, morphological differences have

528 generally been noted (50), which makes species designation plausible. Finally, we treat the records of

529 two small species (Palaeogale minuta and Palaeogale sectoria) from North America and Eurasia as

530 distinct continental endemics, since both persist on both continents for many million years and it

531 seems biologically implausible for them to maintain population coherence (i.e., gene flow) during that

532 time interval. A full breakdown of records by database can be found in the attached Excel spreadsheet

533 'Database summary'.

534

$535 \quad$ 5.1.2 Phylogenetic and dating analyses

536 The phylogeny of all extant and extinct species of carnivores was constructed using a tip dating 537 approach under a fossilised birth-death model in MrBayes 3.2 (43). The phylogeny was created by 538 combining a backbone phylogeny with 17 smaller phylogenies (for Amphicyonidae, Barbourofelidae, 539 Canidae, Eupleridae, Felidae, Herpestidae, Hyaenodontidae, Hyaenidae, Mustelidae, Nimravidae, 540 Oxyaenidae, Palaeogale, Percrocutidae, Pinnipedia, Ursidae, Viverravidae and Viverridae). This 541 procedure requires that all the smaller phylogenies have a known number of species. For two families

542 (Miacidae and Stenoplesictidae) that were not constrained to be monophyletic (see next section), we, 543 therefore, included all species in the backbone phylogeny. Two chains were run for both the backbone 544 and the 17 smaller phylogenies until the average standard deviation of split frequencies was lower than 5450.03 , but for a minimum of 10 million generations. The analyses were further inspected with Tracer

$546 \quad 1.6(51)$ to ensure that the Effective Sample Size of the post burn-in for the overall model tree

547 likelihood for the two chains combined was at least 200.

549 from Ronquist et al (52). In particular, we set a uniform prior of the root between 56.3 and $88.0 \mathrm{Ma}$,

550 representing the span between the oldest fossil in the database and the estimated divergence time

551 between the MRCA of Hyaenodontidae and Carnivora and their combined outgroup, following 
552 Ronquist et al. (52). We further penalised long 'ghost lineages' (i.e. lineages existing for very

553 extended time periods without leaving any fossil evidence) in all analyses using the prior "prset

554 fossilizationpr $=$ beta $(100,1)$ " as also suggested by Ronquist et al (52). For all phylogenetic

555 reconstructions, we assumed that all species are included in the analyses. While we have included all

556 known species in the phylogeny, we acknowledge that a fraction of undescribed species must be

557 missing, but this fraction cannot be reliably estimated with any available method.

The backbone phylogeny was constructed based on morphological data for extinct

clades and a combination of morphological and genetic data for extant ones. All morphological data

were analysed under an MK-model conditioned to only include variable sites and incorporating gamma rate heterogeneity. The morphological data were based on the matrix by Wesley-Hunt and Flynn (53) but supplemented by numerous studies (see Table S9). We added new data for four key taxa representing taxonomic groupings not included in previous analyses (Percrocuta sp, morphological matrix was supplemented with genetic data from Meredith et al (54). To facilitate the merging of the smaller phylogenies with the backbone phylogeny, we added the oldest known species of each family (in this and all other cases we use the ages as listed in the original data source) to the backbone analysis, with all characters coded as missing data. The 17 smaller phylogenies were for the most part constructed based on one or more morphological data matrices, with genetic data also included for the extant families. Depending on the family, the genetic data were either based almost entirely on a single source although with supplemented searches for missing data of missing species from NCBI, or on NCBI searches for each species (a list of sources can again be found in Table S9). based on AIC as inferred by Partitionfinder 1.1 (55) for both the overall and the smaller phylogenies. We set the age of all fossil taxa and all extant species without genetic data to the age of the oldest

577 known record. Six of the species not included in either NOW or PBDB (Amphicynodon brachyrostris, 578 Amphicynodon cephalogalinus, Amphicynodon chardini, Amphicynodon crassirostris, Phoberogale 
580 between the age of the oldest and youngest species in the genus, whereas the sixth (Filholictis filholi)

581 is from a monospecific genus and was given a uniform prior between the youngest and oldest member

582 of the subfamily. For all genera constrained to be monophyletic (see next section), we set the

583 minimum age of the genus to the age of the oldest record in the genus (whether identified to species or

584 not). We did this using a uniform prior on the node age, with a maximum age equal to the rootage of

585 the family. We set the prior on the age of all tips representing fossil species and all extant species

586 lacking genetic data as a uniform prior ranging between the minimum and maximum ages of the oldest

587 known fossil of the species. These are intended to inform the origination time for the species lacking

588 genetic data. For all later analyses, they are treated in the same way as the extant taxa.

$589 \quad$ We merged the smaller trees with the backbone phylogeny while keeping the dating

590 information for both sets, as described below. For the 17 smaller phylogenies, we set a uniform prior

591 of the rootage between the oldest known fossil in the group and the upper 95\% HPD (Highest

592 Posterior Density) for the stem age of the group from the backbone phylogeny. The backbone and the

593 smaller phylogenies were merged so that there was the same correlation between the stem and crown

594 age as between the age of the stem age and the next internal branch in the phylogeny. That is, since

595 Felidae and Barbourofelidae are sister families, the phylogenies were merged so the correlation

596 between the stem and rootage of Felidae is the same as the correlation between the stem age of Felidae

597 and the age of the MRCA (Most Recent Common Ancestor) of Felidae and Barbourofelidae.

598 For some trees, the resulting family-level clades had crown ages slightly older than the

599 stem ages of the overall tree, and we, therefore, needed to recalibrate the family level trees to avoid

600 negative branch lengths. This was done for all problematic trees (i.e. family level trees with crown

601 ages slightly older than the stem ages from the backbone tree) so that all branch lengths in the new tree

602 were proportional to the branches in the original tree, and the rootage was equal to the stem age of the

603 backbone tree minus 0.01 .

604

\section{$605 \quad 5.1 .3$ Constraints}

606 Similar to the assumption of other complete phylogenies, where a number of species lack genetic or

607 morphological data (e.g. 44, 45), we assumed taxonomic clades to be monophyletic unless there is 
good evidence against it. This meant that we carefully inspected the paleontological literature regarding each taxonomic unit to judge if they are generally understood to comprise monophyletic entities (all taxonomic constraints are shown in the attached Excel spreadsheet 'Database summary'). constrained to be monophyletic. Within Carnivoramorpha, Carnivora and Viverravidae, but not Miacidae (which is a paraphyletic assembly; see e.g. 53), were constrained to be monophyletic. Within

614 Carnivora, all taxa were constrained to be either Caniformia or Feliformia. Within Caniformia, we constrained the monophyly of Amphicyonidae, Canidae, Musteloidea, Pinnipedia, and Ursidae and assumed Lycophocyon hutchisoni to be outside any of the major lineages. Within Feliformia we constrained the monophyly of Barbourofelidae, Eupleridae, Felidae, Herpestidae, Hyaenidae, Nimravidae, Percrocutidae, Prionodontidae, and Viverridae, but not Stenoplesictidae (which again is generally considered a paraphyletic assemblage; see e.g. 56). This means that we assumed that each genus normally assigned to Stenoplesictidae, as well as Palaeogale, was outside any of the major lineages listed above. We further constrained Percrocutidae as sister to Hyaenidae following (57) and Felidae as sister to Barbourofelidae following (58). The morphological dataset started by Wesley-Hunt and Flynn (53) was designed to determine the relatedness between basal taxa and on its own (i.e. without genetic data added) produces improbable relationships between more derived members of extant families within Carnivora. (53). Both Percrocutidae and Barbourofelidae are only known from Miocene fossils, meaning that the morphological matrix may be suboptimal to infer their placement, but unlike the extant families, their relationship cannot be inferred by adding genetic data to the analysis. deviated from this in a number of cases for three main reasons: 1) Some of the earliest described genera within families and subfamilies, e.g. Lutra for otters, have served as waste-baskets for a number of frequently poorly-defined fossil taxa (59). Many fossil forms within such genera, as well as other poorly known taxa, were therefore allowed to be placed freely within the family or subfamily instead of being constrained to their genera; 2) Other species of uncertain phylogenetic placement 
636 not constrained to be within otherwise constrained subfamilies or tribes; and 3) Taxonomy does not

637 always imply genus-level monophyly. For some taxa, there is evidence that named genera are nested

638 within other named genera and we, therefore, allowed such nesting when supported. For example, this

639 is the case for Neovison (the American mink and the extinct sea mink), which phylogenetically may be

640 nested within Mustela (weasels) (60).

641 In addition to these taxonomic constraints, we also employed a number of constraints

642 based on stated likely relationships in taxonomical treatments. Finally, we employed a number of

643 biogeographical constraints within lineages or species and often enforced that there would only be a

644 single intercontinental dispersal within a lineage unless there are data to suggest otherwise. A full

645 breakdown of family, subfamily and genus level constraints can be found as part of appendix 2, which

646 contains information on all fossil records and our treatment of them, while a full list of additional

647 constraints and the relevant sources can be found in Table S10.

648

$649 \quad$ 5.1.4. Extinction times

650 The procedure described above only gives the origination times of all lineages, but not the extinction

651 times. To estimate the actual extinction times for all taxa we used the Bayesian program PyRate (45).

652 We did this independently for each continent, which means that we treat a species occurring on

653 multiple continents as two distinct populations that may go extinct independently of each other, rather

654 than as a coherent group of sub-populations with ongoing gene flow.

Firstly, we combined fossil records from NOW and PBDB, keeping as many records as

656 possible while avoiding duplicate records. For each species, we initially accepted all records in either

657 NOW or PBDB (whichever had most records of the species in question). We then examined all

658 records of the other database for the same species, one by one, to assess if they were clearly distinct (in

659 which case they were added) or potential duplicates (in which case they were not). If the latitude and

660 or longitude rounded to the nearest degree was different from all records already accepted, and/or if

661 the age of the record was non-overlapping with accepted records with the same latitude and longitude,

662 we added the record. If there was only one record already accepted with identical latitude and

663 longitude and overlapping age, we considered the old and new ones to be potential duplicates and 
retained the one with the most precise dating. However, we discarded the new record if there was more than one already accepted record with the identical latitude and longitude and overlapping age.

America, Asia, Europe, and Africa, with an additional separate analysis for Pinnipeds (since marine species may have different fossilization potential than terrestrial ones). Sampling intensity (i.e. the product of the number of specimens fossilizing and the fraction of fossils that are identified and placed in the available databases) is a vital component determining how long after the youngest record the true extinction time is likely to have been. Sampling intensity may vary between continents and between marine and terrestrial species. For each continent (and for pinnipeds) we ran 20 separate PyRate analyses, further allowing for variable sampling intensity in each epoch, for example as a consequence of different amounts of exposed rocks of different ages. The analyses of African and South American records (which had fewer records) were run for 10 million generations, whereas all others were run for 20 million generations. Not all analyses converged but we generally used the results from 10 separate chains, where the effective sample size for all key parameters was high (i.e. all parameters related to the overall process but not necessarily the speciation or extinction time of each species, which are treated as individual parameters, had an effective sample size above 200). The exception for this was Europe, where convergence by these criteria was only seen in four chains and only these four were therefore used in the subsequent analyses. origination times estimated from the phylogenetic analyses. We first sampled random generations across the different PyRate analyses (with the same number of samples for each). Following this, we combined the results from a random PyRate generation with a random tree from the posterior distribution. By doing this, we estimated the extinction time for every species on one continent independently of their extinction time on other continents, which means that we consider them to represent separate distinct populations rather than meta-populations with ongoing gene flow. We treated Eurasia as a continent for all downstream analyses rather than as the distinct continents of

690 Europe and Asia. In doing this we set the Eurasian extinction date as the latest of the inferred 
$693 \quad 5.2$ Data analyses

$694 \quad$ 5.2.1 Dispersal inference

695 The first analytical step was an estimation of the dispersal dynamics between continents. For this and

696 all further analyses we discarded pinnipeds (which were just included in the datamining elements to

697 maximise the use of our created phylogeny for future evolutionary studies) and thus only analysed

698 terrestrial species. We estimated ancestral geographic range for all nodes with a DEC

699 (dispersal-extinction-cladogenesis) model in BiogeoBEARS (47), using the trees with origination time

700 as described above. We used a DEC rather than the frequently used DEC $+\mathrm{j}$ model since the

701 underlying mathematical properties of the DEC $+\mathrm{j}$ model have been seriously questioned (48).

702 We manually specified settings in BiogeoBEARS to match the study system. We did

703 not allow dispersal to South America prior to 10 million years ago (Ma). The oldest carnivore fossils

704 from the continent within our database are two records of the procyonid genus Amphinasua dated to

705 6.8-9 Ma; i.e. the Huayquerian South American Land Mammal Age (SALMA). By doing this we

706 assume that at most one SALMA (the Chasicoan, 9-10 Ma) could lack fossils, even though carnivores

707 actually could be present. We only allowed dispersal between adjoining continents (Africa/Eurasia,

708 Eurasia/North America, and North America/South America). Finally, we allowed the dispersal rate in

709 the Pleistocene (and Holocene) to be potentially higher than the pre-Pleistocene dispersal rate but

710 otherwise kept a single constant dispersal rate. BiogeoBEARS does not generally allow temporal

711 variation in dispersal rates, unless the relative temporal rates are manually specified, but we allowed

712 the dispersal rate in the Pleistocene to be different from the pre-Pleistocene rate by setting the

713 Pleistocene rate as $\mathrm{d}_{\text {Pleistocene }}=\mathrm{d}_{\text {Pre-Pleistocene }} * 2^{w}$, with $w$ being a free parameter estimated by

714 BiogeoBEARS.

715 As a second step, we transformed the probabilistic ancestral states at all nodes of the

716 DEC analysis into binary presence/absences by sampling values based on the estimated probabilities.

717 This was done starting with the most terminal nodes. While sampling ancestral nodes, we only

718 sampled among states that were reasonable considering the states of the descendant nodes. Thus, if the 
719

estimated ancestral state of two daughter nodes was inferred to be Eurasia and North America, the ancestral area of their direct ancestor was restricted to combinations of one or both of these two areas.

$$
\text { Finally, we estimated dispersal times between continents. Whenever mechanistically }
$$

plausible (e.g. if the ancestor lived in North America and the daughter species lived in Eurasia and North America) dispersal was inferred to be at the time of speciation. When this was not the case, the necessary dispersal events (and potential required extinction events) were placed equidistant from each other on the relevant branches.

We acknowledge that the procedure of assigning areas to nodes and branches can be seen as a violation from the DEC model the data was estimated under, but we consider these violations biologically justifiable. Our estimation procedure means that we can infer jump dispersal whenever it is possible. These do not exist under a standard DEC model, but due to mathematical problems with the extension that explicitly incorporates jump dispersal (DEC+j model), we preferred to use this workaround. If we instead had used stochastic mapping to infer ancestral areas, we would have drastically overestimated the magnitude of dispersal events - especially ones taking place along long branches. This is because the only way to generate the frequent range changes that can be seen for rapidly diversifying clades without having jump dispersal in the model is by having unrealistically high dispersal rates within lineages. To get an idea of the magnitude of this issue, we estimated ancestral areas through stochastic mapping ten times for each of the 100 trees. We found that the smallest overestimation among all these 1,000 replicates was $47 \%$ while the median overestimation was $71 \%$. The overestimation of dispersal events based on stochastic mapping would be particularly problematic for our analyses, due to its concentration on longer branches, which would produce biased results in our analyses of the relationship between dispersal rate and diversification.

\subsubsection{Statistical analyses}

We conducted a number of separate analyses on 100 separate trees from the posterior distribution. These analyses dealt with the dispersal dynamics between continents, the build-up of diversity and the macro-evolutionary success of intercontinental dispersers relative to other species. In all cases 
746 described below, we analysed the patterns in standard regression analyses with the results from each of

747 the 100 trees weighted equally. meaningfully interpretable for ultrametric trees. For simplicity, extinction was therefore dealt with in

750 time intervals and on trees sliced at various ages, rather than in continuous time, counting only the

751 species (internal or external branches) extant at that time point. Hence, when using 0.5-million-year

752 time intervals, two species that went extinct 1.2 and 1.4 Ma would both be included as extant for a tree

753 sliced at 1.0 Ma (but extinct in a tree sliced at $0.5 \mathrm{Ma}$ ). All analyses were conducted with time

754 intervals of $0.25,0.5$ or 1.0 million years duration in order to test the effect of this procedure on the 755 results.

In the simplest analyses, we calculated species diversity and phylogenetic diversity (49)

757 (i.e. the sum of the branch lengths in the tree) for all species alive in each time interval globally or on each continent. In two other sets of analyses, we tested whether dispersing species were diversifying faster than others were. The first of these sets of analyses, which we call pre-dispersal success, investigated if species that disperse belong to lineages that, at their time of dispersal, diversified faster than the other lineages present at that point in time. The second, which we call post-dispersal success, investigated if species that disperse leave more descendant species than species that do not disperse. We estimated pre-dispersal success based on the diversification rate (DR) (45). We sliced the tree at the end of each time interval throughout the Cenozoic and calculated the DR of all lineages alive at that time. For all intercontinental dispersal events occurring in the following time interval, we then identified the lineage representing the disperser (this could be either the same species or one of its ancestors). We then calculated the logarithm of the ratio between the diversification rate of the disperser and the median diversification rate for either all lineages alive in the time interval (global pre-dispersal success) or the subset of these that was found on the same continent the disperser originated in (continental pre-dispersal success). This calculation is outlined in Fig. 3. with a tree sliced a number of million years afterwards. For each lineage alive at the first time interval, 
774 the lineage had gone extinct in the meantime). We then calculated the ratio between the number of

775 species in the dispersing lineage and the mean for either all other species (global post-dispersal

776 success) or all species from the continent dispersal is to (continental post-dispersal success). In both

777 cases, we square-root transformed the post-dispersal success to improve normality. For this measure,

778 we used square-root rather than log transformation and means rather than medians, because zero

779 descendants for both the dispersing and non-dispersing lineages are common. Zero descendants for the

780 dispersing lineages could otherwise require taking the logarithm to zero, while zero descendants for

781 the non-dispersers (if occurring for more than half the species) would otherwise require dividing by

782 zero. Dispersal events were ignored for these analyses if they occurred so recently that the time period

783 a few million years later than that which we compare them to would be in the future. Separate analyses

784 of post-dispersal success were conducted on trees sliced after 3, 5, and $7 \mathrm{My}$ (with all dispersal events

785 occurring within the last 3, 5, or 7 My ignored).

786

$787 \quad$ 5.2.3 Simulations

788 All analyses described in 5.2.2 implicitly assume complete sampling. Although we have included all

789 known species, an unknown number of extinct species may be missing from the fossil record, which

790 can influence our results. This is especially so since the fraction of missing species is expected to vary

791 in time and space. In order to understand the influence of missing taxa on our results, we, therefore,

792 simulated a number of random phylogenies. We then simulated incomplete sampling on those

793 phylogenies, then repeated all analyses described in 5.2.2 on both the full and the sampled

794 phylogenies.

We simulated trees based on a stage-dependent speciation and extinction model. More

specifically, we simulated trees based on a seven-class ClaSSE (Cladogenetic State change Speciation and Extinction) model (61) modified into a four-area version of the normally two-area GeoSSE model (62) using Diversitree (63). In this version, each species was given seven potential character states 1:

799 S, 2; SN, 3: N, 4: NE, 5: E, 6: EA, 7: A (where S means South America, N means North America, E 800 means Eurasia and A means Africa). The model included five parameters: sympatric speciation rate 801 ( $\lambda 1)$ present in all classes; jump dispersal speciation $(\lambda 2)$ for single area classes; allopatric speciation 
802 ( $\lambda 3$ ) for two area classes; local extinction rate $(\varepsilon)$; and dispersal rate $(\delta)$ only between adjoining 803 regions. The model is outlined in Fig. S2. sampler to obtain a distribution of trees resembling the empirical ones in shape and geographic ranges.

806 We obtained the ClaSSE parameter values by randomly drawing them from the following uniform 807 distributions: $\lambda 1 \sim \mathrm{U}(0,0.2), \lambda 2 \sim \mathrm{U}(0,0.05), \lambda 3 \sim \mathrm{U}(0,3), \delta \sim \mathrm{U}(0,0.1)$, and $\varepsilon \sim \mathrm{U}(0,0.4)$. We 808 generated phylogenetic trees and geographic ranges at each random draw. The rejection sampler 809 included three summary statistics: 1) the fraction of all taxa that are extant;2) the total number of 810 dispersals; and 3) the number of extant species occurring on more than one continent. Phylogenetic 811 trees and geographic ranges were only accepted if all summary statistics met the condition: $x_{\text {sim }} / x_{\text {emp }} \in[2 / 3,1.5]$, where $\mathrm{x}_{\text {sim }}$ is the statistic obtained from the simulation (e.g. the total number of dispersals) and $\mathrm{x}_{\mathrm{emp}}$ is the corresponding value obtained from the empirical data. We repeated the simulation until 100 trees were accepted. The branch lengths of these trees were then multiplied by the appropriate factors to have root ages corresponding to those of the 100 empirical trees. random trees based on estimated sample intensity at each epoch as inferred from the PyRate analysis (see 4.1.4). We assumed complete sampling of extant species. Sample intensity for the PyRate analysis was estimated separately for Asia and Europe, due to the large difference in paleontological research conducted in the two continents. For all biogeographical analyses, however, we used a combined

821 Eurasia since the borders between the two are poorly defined and a large fraction of species have 822 ranges spanning both continents. For the simulations (which are intended to mimic the 823 biogeographical analyses), we, therefore, used a combined value for Eurasian sampling. This was 824 estimated as the mean of the European and Asian sampling weighted by the contemporary diversity of 825 carnivores in the two continents. No pre-Miocene South American carnivores exist in the empirical 826 trees and therefore we cannot use empirical values for this continent for the Paleocene, Eocene, and

827 Oligocene. We instead used the mean estimate for Africa and Eurasia (corresponding to substantially 828 lower estimated sampling effort than North America). Estimation of sample intensity in PyRate can be 
829 imprecise for very shallow time intervals such as the Holocene (Daniele Silvestro, pers. comm.). We,

830 therefore, used the Pleistocene value for both the Pleistocene and Holocene.

831 We carried out one round of random sampling based on the preservation rate defined

832 above for each continent, separately for each branch. We first assessed sampling on all external

833 branches on all continents and accepted presence whenever sampling was simulated to have taken

834 place. After this, we assessed internal branches ranked in order of increasing number of descendants.

835 Whenever an internal branch occurred on, and was sampled in, a continent where none of its occurring

836 descendants were sampled, we considered a random descendant species on the relevant continent as

837 sampled instead. The logic of this treatment can be understood by looking at a small clade of two

838 species, with a long internal branch and an extinction of both species nearly immediately after

839 speciation. In such cases, the probability of sampling both species would be limited but it is more

840 likely that we would sample the lineage before speciation. If we only looked at sampling in external

841 branches, we would thus drastically underestimate the diversity resulting from incomplete sampling.

842 In order to test the importance of incomplete sampling, we repeated all analyses from

8435.2 .2 on both the full random trees and the random trees with simulated sampling. After this, we

844 assessed if the effects we observed in the empirical trees matched the differences between the

845 simulated trees with incomplete and complete sampling, in which case extreme care would be needed

846 in the interpretation of the results.

847

Additional references

50) Tedford, R. H. \& Gustafson, E. P. First North American record of the extinct panda Parailurus. Nature 265, 621-623 (1977) in bayesian phylogenetics using Tracer 1.7. Syst. Biol. 67, 901-904 (2018) total-evidence dating. Philos. Trans. Royal Soc. B 371, 20150136 (2016) 
53) Wesley-Hunt, G., \& Flynn J. J. Phylogeny of the Carnivora: basal relationships among the carnivoramorphans, and assessment of the position of Miacoidea relative to Carnivora. J. Syst. Palaeontol. 3, 1-28 (2005)

54) Meredith, R. W. et al. Impacts of the Cretaceous Terrestrial Revolution and KPg extinction on mammal diversification. Science 334, 521-524 (2011)

55) Lanfear, R., Calcott, B., Ho, S. Y. W. \& Guindon, S. PartitionFinder: combined selection of partitioning schemes and substitution models for phylogenetic analyses. Mol. Biol. Evol. 29, 1695-1701 (2012)

56) Werdelin L. \& Peigne, S., in Cenozoic Mammals of Africa. (eds. Werdelin, L., \& Sanders W. J.) 603-658 2010. (University of California Press, 2010)

57) Figueirido, B., Tseng, Z. J. \& Martin-Serra, A. Skull shape evolution in durophagous carnivorans. Evolution 67, 1975-1993 (2013)

58) Morlo, M., Peigné, S. \& Nagel, D. A new species of Prosansanosmilus: implications for the systematic relationships of the family Barbourofelidae new rank (Carnivora, Mammalia). Zool. J. Linn. Soc.140, 43.61 (2004)

59) Willemsen, G. A revision of the Pliocene and Quaternary Lutrinae from Europe. Scripta Geologica 101, 1-115 (1992)

60) Koepfli, K. P. et al. Molecular systematics of the Hyaenidae: relationships of a relictual lineage resolved by a molecular supermatrix. Mol. Phylogenet. Evol. 38, 603-620 (2006)

61) Goldberg, E. E. \& Igić, B. Tempo and mode in plant breeding system evolution. Evolution 66, 3701-3709 (2012)

62) Goldberg, E. E., Lancaster, L. T. \& Ree, R. H. Phylogenetic inference of reciprocal effects between geographic range evolution and diversification. Syst. Biol. 60, 451-465 (2011)

63) Fitzjohn, R. G. Diversitree: comparative phylogenetic analyses of diversification in R. Methods Ecol. Evol. 6, 1084-1092 (2012)

64) Cirot, E. \& Bonis, L. Révision du genre Amphicynodon, carnivore de l'Oligocène. Palaeontographica Abteilung A 220, 103-130 (1992) 
65) Wang, X. \& Tedford, R. H. The Status of genus Nothocyon Matthew, 1899 (Carnivora): an Arctoid not a Canid. J. Vert Paleontol. 12, 223-229 (1992)

66) Kordikova, E. G., Heizmann, E. P. J. \& Mavrin, A. V. Early Miocene Carnivora of Aktau Mountains South Eastern Kazakhstan. Palaontologische Zeitschrift 74, 195-204 (2000)

67) Peigné, S. \& Heizmann, P. J. The amphicyonidae (mammalia: carnivora) from Ulm-

68) Ginsburg, L. Les faunes de mammifères terrestres du Miocène moyen des Faluns du bassin de Savigné-sur-Lathan (France). Geodiversitas 23, 381-394 (2001)

69) Hunt, R. M. Long-legged pursuit carnivorans (Amphicyonidae, Daphoeninae) from the early Miocene of North America. Bull. Am. Mus. Nat. Hist. 318, 1-95 (2009)

70) Raza, S. M., Barry, J. C., Meyer, G. E. \& Martin, L. Preliminary report on the geology and vertebrate fauna of the Miocene Manchar Formation, Sind, Pakistan. J. Vert. Paleontol. 4, 584-599 (2010)

71) Rybczynski, N., Dawson, M. R. \& Tedford, R. H. A semi-aquatic Arctic mammalian carnivore from the Miocene epoch and origin of Pinnipedia. Nature 458, 1021-1024 (2009)

72) Hartstone-Rose, A., Kuhn, B. F., Nalla, S., Werdelin, L. \& Berger, L. R. A new species of fox from the Australopithecus sediba type locality, Malapa, South Africa. T. Roy. Soc. S. Afr. 68 , $1-9(2013)$

73) Werdelin, L. A new genus and species of Felidae (Mammalia) from Rusinga Island, Kenya, with notes on early Felidae of Africa. Estudios Geológicos 67, 217-222 (2012)

74) Peigne, S. Proailurus, l'un des plus anciens Felidae (Carnivora) d'Eurasie : systématique et évolution. Bulletin du Museum National d'Histoire Naturelle Toulouse 135, 125-134 (1999)

75) Salesa, M. J., Anton, M., Morales, J. \& Peigne, S. Systematics and phylogeny of the small felines (Carnivora, Felidae) from the Late Miocene of Europe: A new species of Felinae from the Vallesian of Batallones (MN 10, Madrid, Spain). J. Syst. Palaeontol. 10, 87-102 (2012) 
76) Spassov, N. \& Geraads, D. A new felid from the Late Miocene of the Balkans and the contents of the genus Metailurus Zdansky, 1924 (Carnivora, Felidae). J. Mamm. Evol. 22, 45-56 (2015)

77) Solé, F., Falconnet, J. \& Yves, L. New proviverrines (Hyaenodontida) from the early Eocene of Europe; phylogeny and ecological evolution of the Proviverrinae. Zool. J. Linn. Soc. 171, 878-917 (2014)

78) Zack, S. P. New species of the rare early Eocene creodont Galecyon and the radiation of early Hyaenodontidae. J. Paleontol. 85, 315-336 (2011)

79) Solé, F. et al. A New Large Hyainailourine from the Bartonian of Europe and Its Bearings on the Evolution and Ecology of Massive Hyaenodonts (Mammalia). PLOS ONE 10, e0141941. (2015)

80) Egi, N. et al. Proviverrine hyaenodontids (Creodonta: Mammalia) from the Eocene of Myanmar and a phylogenetic analysis of the proviverrines from the Para-Tethys area. $J$ Syst. Palaeontol. 3, 337-358 (2005)

81) Schmidt-Kittler, N. et al. European reference levels and correlation tables. Münchner Geo wissenschaftliche Abhandlungen A 10, 13-31 (1987)

82) Lavrov, A. V. New Species of Paroxyaena (Hyaenodontidae, Creodonta) from Phosphorites of Quercy, Late Eocene, France. Paleontol. J. 41, 298-311 (2007)

83) Werdelin, L. \& Solounias, N. The Hyaenidae: taxonomy, systematies and evolution. Fossils and Strata 30, 1-104 (1991)

84) Werdelin, L. \& Lewis, M. E. New species of Crocuta from the early Pliocene of Kenya, with an overview of early Pliocene hyenas of eastern Africa. J. Ver. Paleontol. 28, 1162-1170 (2008)

85) Wang, X. \& Qui, Z. Late Miocene Promephitis (Carnivora, Mephitidae) from China. J. Ver. Paleontol. 24, 721-731 (2004)

86) Spaulding, M., Flynn, J. J. \& Stucky, R. K. A new basal Carnivoramorphan (Mammalia) from the 'Bridger B' (Black's Fork member, Bridger Formation, Bridgerian Nalma, middle Eocene) of Wyoming, USA. Palaeontology 53, 815-832 (2010) 
87) Smith, T. \& Smith, R. A new genus of "miacid" carnivoran from the earliest Eocene of Europe and North America. Acta Palaeontol. Pol. 55, 761-764 (2010)

88) Solé, F. New carnivoraforms from the early Eocene of Europe and their bearings on the evolution of the Carnivoraformes. Palaeontology 57, 963-978 (2014)

89) Harrison, D. L., Bates, P. J. J., Pearch, M., Michaels, C. \& Ward, D. J. New additions to the

90) Heinrich, R. E., Strait, S. G. \& Houde, P. Earliest Eocene Miacidae (Mammalia: Carnivora) from Northwestern Wyoming. J. Paleontol. 82, 154-162 (2008)

91) Solé, F., Smith, R., Coillot, T., de Bast, E. \& Smith, T. Dental and tarsal anatomy of 'Miacis' latouri and a phylogenetic analysis of the earliest carnivoraforms (Mammalia, Carnivoramorpha), J. Vert. Paleontol. 34, 1-21 (2014)

92) Raghavan, P., Pickford, M., Patnaik, R. \& Gayathri, P. First fossil small-clawed otter, Amblonyx, with a note on some specimens of Lutra, from the Upper Siwaliks, India. Estudios Geológicos 63, 135-146 (2007)

93) Werdelin, L. \& Lewis, M. E. The Carnivora. Koobi Fora Research Project, Vol. 7. (California Academy of Sciences, 2013)

94) Valenciano, A., Abella, J., Göhlich, U. B., Álvarez-Sierra, M. A. \& Morales, J. Re-evaluation of the very large Eomellivora fricki (Pia, 1939) (Carnivora, Mustelidae, Mellivorinae) from the Late Miocene of Austria. Palaeontol. Electron. 20.1.17A, 1-22 (2017)

95) Wolsan, M. \& Sotnikova, M. Systematics, evolution, and biogeography of the Pliocene stem meline badger Ferinestrix (Carnivora: Mustelidae). Zool. J. Linn. Soc. 167, 208-226 (2013)

96) Lim, J. D. \& Martin, L. D. A new fossil mustelid from the Miocene of South Dakota, USA Naturwissenschaften 89, 270-274 (2002) Pleistocene of Pantalla (Italy), with remarks on the evolutionary history of Mediterranean Quaternary Lutrinae (Carnivora, Mustelidae). Quat. Sci. Rev. 135, 92-102 (2016) 
98) Colombero, S., Pavia, M. \& Rook, L. Pannonictis nestii (Galictinae, Mustelidae), a new element in the vertebrate association of the human site of Pirro Nord (Italy, Early Pleistocene). Geodiversitas 34, 665-681 (2012)

99) Lim, J. D. \& Martin, L. D. A new primitive Leptarctine (Mustelidae) from the North American Miocene. Neues Jahrbuch für Geologie und Paläontologie. 2000, 632-640 (2000)

100) Morales, J. \& Pickford, M. Giant bunodont Lutrinae from the Mio-Pliocene of Kenya and Uganda. Estudios Geológicos 61, 233-246 (2005)

101) Tseng, Z. J., Wang, X. \& Stewart, J. D. A new immigrant mustelid (Carnivora, Mammalia) from the middle Miocene Temblor Formation of central California. PaleoBios 29, $13-23(2009)$

102) Bonis, L. Précisions sur l'âge géologique et les relations phylétiques de Mustelictis olivieri nov. sp. (Carnivora, Mustelidae), carnassier de l'Oligocène inférieur (MP 22) des phosphorites du Quercy (France). Geobios 20, 55-60 (1997)

103) Lange, B. Un nouveau Mustaline des phosphorites du Quercy Mustelictis piveteaui. Comptes rendus de l'Acaddmie des Sciences de Paris, D 268, 2870-2872 (1969)

104) Barett, P. Z. Taxonomic and systematic revisions to the North American Nimravidae (Mammalia, Carnivora) PeerJ 4, e1658 (2016)

105) Peigne, S. New species of Eofelis (Carnivora: Nimravidae) from the Phosphorites of Quercy, France. Comptes rendus de l'Acaddmie des Sciences de Paris, D 330, 653-658 (2000) 106) Averianov, A., Obraztsova, E., Danilov, I., Skutschas, P. \& Jin, J. First nimravid skull from Asia. Sci. Rep. 6, 25812. (2016)

107) Forasiepi, A. M. et al. Carnivorans at the Great American Biotic Interchange: new discoveries from the northern neotropics. Naturwissenschaften 101, 965-974 (2014)

108) Wolsan, M. \& Lange-Badre, B. An arctomorph carnivoran skull from the Phosphorites du Quercy and the origin of procyonids. Acta Palaeontol. Pol. 41, 277-298. (1996)

109) Hunt, R. M. Evolution of the Aeluroid Carnivora: Diversity of the earliest Aeluroids from Eurasia (Quercy, Hsanda-Gol) and the origins of felids. Am. Mus. Novit. 3252, 1-33 (1998) 
1001

1002

1003

1004

1005

1006

1007

1008

1009

1010

1011

1012

1013

1014

1015

1016

1017

1018

1019
110) Peigné, S. \& Bonis, L. The genus Stenoplesictis Filhol (Mammalia, Carnivora) from the Oligocene deposits of the Phosphorites of Quercy, France. J. Vert. Paleontol. 19, 566-575 (1999)

111) Bonis, L. A new species of Adelpharctos (Mammalia, Carnivora, Ursidae) from the late Oligocene of the "Phosphorites du Quercy" (France). Estudios Geológicos 67, 179-186 (2012)

112) Abella, J. et al. Kretzoiarctos gen. nov., the oldest member of the giant panda clade. PLoS ONE 7, e48985. (2012)

113) Ogino, S., Egi, N., Maung-Thein, Z. M., Htike, T. \& Takai, M. New species of Agriotherium (Mammalia, Carnivora) from the late Miocene to early Pliocene of central Myanmar. J. Asian Earth Sci. 42, 408-414 (2011)

114) Soibelzon, L. H. \& Schubert, B. W. The largest known bear, Arctotherium angustidens, from the early Pleistocene Pampean region of Argentina: with a discussion of size and diet trends in bears. J. Paleontol. 85, 69-75. (2011)

115) Bonis, L. Ursidae (Mammalia, Carnivora) from the Late Oligocene of the "Phosphorites du Quercy" (France) and a reappraisal of the genus Cephalogale Geoffroy, 1862.

Geodiversitas 35, 787-814. (2013)

116) Zhan-Xiang, Q., Tao, D. \& Ban-Yue, W. A Late Miocene Ursavus skull from Guanghe, Gansu, China. Vertebrata Palasitica 52, 265-302 (2014)

117) Meehan, T. J. \& Wilson, R. W. New Viverravids from the Torrejonian (Middle Paleocene) of Kutz Canyon, New Mexico and the oldest skull of the Order Carnivora. $J$. Paleontol. 76, 1091-1101 (2002)

118) Beard, K.C. \& Dawson, M. R. Early Wasatchian mammals of the red hot local fauna, uppermost Tuscahoma formation, Lauderdale County, Mississippi. Ann. Carnegie Mus. 78, $193-243(2009)$

119) Morales, J. \& Pickford, M. A new paradoxurine carnivore from the Late Miocene Siwaliks of India and a review of the bunodont viverrids of Africa. Geobios 44, 271-277 (2011) 
121) Spaulding, M. \& Flynn, J. J. Phylogeny of the Carnivoramorpha: The impact of postcranial characters. J. Syst. Palaeontol. 10, 653-677 (2012)

122) Jian, W. \& Zhao-Qun, Z. Phylogenetic analysis on Palaeogale (Palaeogalidae,

Carnivora) based on specimens from Oligocene strata of Saint-Jacques, Nei Mongol.

Vertebrata Palasiatica 10, 310-334 (2015)

123) Peigné, S., Salesa, M. J., Anton, M. \& Morales, J. A new Amphicyonine (Carnivora:

Amphicyonidae) from the Upper Miocene of Batallones-1, Madrid, Spain. Palaeontology 51, 943-965 (2008)

Eocene 'Miacis' from Texas, USA, and the origin of Amphicyonidae (Mammalia, Carnivora).

125) Robles, J. M. et al. New craniodental remains of the barbourofelid Albanosmilus jourdani (Filhol, 1883) from the Miocene of the Vallès-Penedês Basin (NE Iberian Peninsula) and the phylogeny of the Barbourofelini. J. Syst. Palaeontol. 11, 993-1022 (2013)

127) Prevosti, F. J. Phylogeny of the large extinct South American Canids (Mammalia, assessment. Science 311, 73-77 (2006) 

origin of big cats. Proc. R. Soc. B 281, 20132686 (2016)

132) Werdelin, L. \& Flink, T. in Smilodon: The Iconic Sabertooth (eds Werdelin, L.,

1050

1051

1052

1053

1054

1055

1056

1057

1058

1059

1060

1061

1062

1063

1064

1065

1066

1067

1068

1069

1070

1071

1072
McDonald, H. G. \& Shaw, C. A.) 14-29 (Johns Hopkins University Press, 2018)

133) Koepfli, K. P. et al. Molecular systematics of the Hyaenidae: relationships of a relictual lineage resolved by a molecular supermatrix. Mol. Phylogenet. Evol. 38, 603-620 (2006)

134) Baskin, J. A. Bassariscus and Probassariscus (Mammalia, Carnivora, Procyonidae) from the early Barstovian (middle Miocene). J. Ver. Paleontol. 24, 709-720. (2004)

135) Finarelli, J. A. A total evidence phylogeny of the Arctoidea (Carnivora: Mammalia): relationships among basal taxa. J. Mamm. Evol. 15, 231-259 (2008)

136) Robles, J. M. et al. New craniodental remains of Trocharion albanense Major, 1903 (Carnivora, Mustelidae), from the Vallès-Penedès Basin (middle to late Miocene, Barcelona, Spain). J. Ver. Paleontol. 30, 547-562 (2010)

137) Wang, X., Carranza-Castañeda, O. \& Aranda-Gómez, J. J. A transitional skunk, Buisnictis metabatos sp. nov. (Mephitidae, Carnivora), from Baja California Sur and the role of southern refugia in skunk evolution. J. Syst. Palaeontol. 12, 291-302 (2014)

138) Fulton, T. L. \& Strobeck, C. Multiple markers and multiple individuals refine true seal phylogeny and bring molecules and morphology back in line. Proc. R. Soc. B 277, 1065-1070 (2010)

139) Berta, A., Kienle, S., Bianucci, G. \& Sorbi, S. A Reevaluation of Pliophoca etrusca (Pinnipedia, Phocidae) from the Pliocene of Italy: Phylogenetic and biogeographic implications. J. Ver. Paleontol. 35, e889144 (2015)

140) Boessenecker, R. W. \& Churchill, M. The oldest known fur seal. Biol. Lett. 11, $20140835(2015)$

141) Cozzuol, M. A. A "northern" seal from the Miocene of Argentina: implications for phocid phylogeny and biogeography. J. Ver. Paleontol. 21, 415-421 (2001) 
142) Kohno, N. Miocene pinniped Allodesmus (Mammalia: Carnivora); with special reference to the" Mito seal" from Ibaraki Prefecture, Central Japan. Trans. Proc. Palaeontol. Soc. Jpn. 181, 388-404 (1996)

143) Koretsky, I. A. \& Rahmat, S. J. A new species of the subfamily Devinophocinae $\mathrm{e} 0131856(2015)$

145) Pages, M. et al. Combined analysis of fourteen nuclear genes refines the Ursidae phylogeny. Mol. Phylogenet. Evol. 47, 73-83 (2008)

146) Wang, X., McKenna, M. C. \& Dashzeveg, D. Amphicticeps and Amphicynodon (Arctoidea, Carnivora) from Hsanda Gol Formation, Central Mongolia and Phylogeny of Basal Arctoids with Comments on Zoogeography. Am. Mu. Novit. 3483, 1-57 (2005) 147) Morlo, M. \& Gunnell, G. F. Small limnocyonines (Hyanodontidae, Mammalia) from the Bridgerian middle Eocene of Wyoming: Thiocyon, Prolimnocyon and Imdodon new genus. Contributions from the Museum of Paleontology, University of Michigan 31, 43-78 (2003) 148) Solé, F. New proviverrine genus from the Early Eocene of Europe and the first phylogeny of Late Palaeocene-Middle Eocene hyaenodontidans (Mammalia). J. Syst.

Palaeontol. 11, 375-398 (2013)

149) Hunt, R. M. Evolution of large carnivores during the Mid-Cenozoic of North America: The temnocyonine radiation (Mammalia, Amphicyonidae). Bull. Am. Mus. Nat. Hist. 358, $1-$ $153(2001)$

150) Hunt, R. M. New amphicyonid carnivorans (Mammalia, Daphoeninae) from the Early Miocene of Southeastern Wyoming. Am. Mus. Novit. 3385, 1-41 (2002)

151) Hunt, R.M. in Evolution of Tertiary Mammals of North America Volume 1: Terrestrial Carnivores, Ungulates, and Ungulatelike Mammals. (eds. Janis, C. M., Scott, K. M. \& Jacobs, L. L.) 196-227 (Cambridge University Press, 1998) 
152) Morales, J., Pickford, M. \& Valenciano, A. Systematics of African Amphicyonidae,

with descriptions of new material from Napak (Uganda) and Grillental (Namibia) J. Iber.

1103

Geol. 42, 131-150 (2016)

1104

1105

1106

1107

1108

1109

1110

1111
153) Wang, X. \& Tedford, R. H. Fossil dogs (Carnivora, Canidae) from the Sespe and

Vaqueros formations in Southern California, with comments on relationships of Phlaocyon taylori. Natural History Museum of Los Angeles County, Science Series 41, 225-272 (2008)

154) Wang, X. New material of Osbornodon from the early Hemingfordian of Nebraska and Florida. Bull. Am. Mus. Nat. Hist. 279, 163-176. (2003)

155) Nyakatura, K. \& Bininda-Emonds, O. R. P. Updating the evolutionary history of Carnivora (Mammalia): a new species-level supertree complete with divergence time estimates. BMC Biology 10, 12 (2012)

156) Bininda-Emonds, O. R. P. et al. The delayed rise of present-day mammals Nature 446, $507-512(2007)$

157) Werdelin, L., Yamaguchi, N., Johnson, W. E. \& O'Brien, S. J. in Biology and Conservation of Wild Felids (eds. Macdonald, D. W. \& Loveridge, A. J.) 59-82 (Oxford University Press, 2010)

158) Seymour, K. L. Panthera onca. Mammalian Species. 340, 1-9 (1989)

159) Barnett, R. et al. Evolution of the extinct sabretooths and the American cheetah-like cat.

Cur. Biol. 15, R589-90. (2005)

160) Werdelin, L. \& Lewis, M. E. A revision of the genus Dinofelis (Mammalia, Felidae).

Zool. J. Linn. Soc. 132, 147-258 (2001)

161) Patou, M. L. et al. Molecular phylogeny of the Herpestidae (Mammalia, Carnivora) with a special emphasis on the Asian Herpestes. Mol. Phylogenet. Evol. 53, 69-80 (2009)

162) Turner, A., Antón, M. \& Werdelin, L. Taxonomy and evolutionary patterns in the fossil Hyaenidae of Europe. Geobios 41, 677-687 (2008)

163) de Bonis, L. et al. Hyaenidae (Carnivora) from the late Miocene of Toros-Mena. J. Afr.

Earth Sci. 58, 561-579 (2010) 
164) Morlo, M. \& Peigne, S. in. Carnivoran Evolution: New views on phylogeny, form, and function page (eds. Goswami, A. \& A. Friscia) 92-140 (Cambridge university press 2010). 165) Sotnikova, M. V. A new species of lesser panda Parailurus (Mammalia, Carnivora) from the Pliocene of Transbaikalia (Russia) and some aspects of ailurine phylogeny.

Paleontol. J. 42, 90-99. (2008)

166) Wang, X. New cranial material of Simocyon from China, and its implications for phylogenetic relationship to the Red Panda (Ailurus). J. Vert. Paleontol. 17, 184-198 (1997) 167) Baskin, J. A. in Evolution of Tertiary Mammals of North America Volume 1: Terrestrial Carnivores, Ungulates, and Ungulatelike Mammals. (eds. Janis, C. M., Scott, K. M. \& Jacobs, L. L.) 152-173 (Cambridge University Press, 1998).

168) Nagel, D., Stefen, C. \& Morlo, M. The carnivoran community from the Miocene of Sandelzhausen (Germany). Paläontologische Zeitschrift 83, 151-174 (2009)

169) Prassack, K. A. Lontra weiri, sp. nov., a Pliocene river otter (Mammalia, Carnivora, Mustelidae, Lutrinae) from the Hagerman Fossil Beds (Hagerman Fossil Beds National Monument), Idaho, U.S.A. J. Vert. Paleontol. 36, e1149075 (2016)

170) Willemsen, G. F. Megalenhydris and its relationship to Lutra reconsidered. Hellenic J.

Geosci. 41, 83-87 (2006)

171) Cherin, M. \& Rook, L. First report of Lutra simplicidens (Carnivora, Mustelidae, Lutrinae) in the Early Pleistocene of the Upper Valdarno (Italy) and the origin of European otters. Ital. J. Geosci. 133, 200-203 (2013)

172) Valenciano, A. et al. Megalictis, the Bone-Crushing Giant Mustelid (Carnivora, Mustelidae, Oligobuninae) from the Early Miocene of North America. PloS ONE 11, e0152430 (2016)

173) Howell, F. C. \& Petter, G. Comparative observations on some middle and upper Miocene hyaenids, Genera: Percrocuta Kretzoi, Allohyaena Kretzoi, Adcrocuta Kretzoi (Mammalia, Carnivora, Hyaenidae). Geobios 18, 419-491 (1985) 

and phylogenetic analysis of Puijila darwini, a transitional pinniped. Canadian Society of Vertebrate Anatomy conference abstracts 2016, 48 (2016) (Mammalia, Carnivora, Otariidae) from the Astoria Formation in coastal Oregon. Contributions in Science 43, 1-27 (1992)

Oregon. J. Vert. Paleontol. 14, 405-413 (2010)

from Trinchera Dolina, Atapuerca (Spain). Comptes Rendus de l'Académie des Sciences Series IIA - Earth and Planetary Science 332, 717-725 (2015)

181) Nagel, D. Carnivores from the Middle Miocene deposits of Grund (Lower Austria).

Annalen des Naturhistorischen Museums in Wien. Serie A für Mineralogie und Petrographie,

$$
\text { Gunnell, G. F. in Evolution of Tertiary Mammals of North America Volume 1: }
$$


Table S1: Continental pre-dispersal success.

The test statistic is the logarithm of the ratio between the diversification rate at the time of dispersal of dispersers and the median of the diversification rates of all species present in the source continent just before the dispersal event (see Fig. 1).

The $\mathrm{p}$-values for the global rate and for the temporal age effect are the probability of being different from 0 . For models with different patterns depending on the source and or target continent, the p-value is based on the probability of being different from the estimated global rate.

\begin{tabular}{|c|c|c|c|}
\hline & $\begin{array}{l}\text { 1.0-million-year } \\
\text { intervals }\end{array}$ & $\begin{array}{l}0.5 \text {-million-year } \\
\text { intervals }\end{array}$ & $\begin{array}{l}0.25 \text {-million-year } \\
\text { intervals }\end{array}$ \\
\hline \multicolumn{4}{|c|}{ Simplest model } \\
\hline Global & $0.0900(0.0199)^{* * * *}$ & $0.0835(0.0194)^{* * *}$ & $0.0785(0.0190)^{* * * *}$ \\
\hline AIC & 126.202 & 120.325 & 122.352 \\
\hline \multicolumn{4}{|c|}{ Temporal variation } \\
\hline Global & $0.1229(0.0260)^{* * * *}$ & $0.1122(0.0259)^{* * *}$ & $0.1068(0.0255)^{* * *}$ \\
\hline Age & $-0.0021(0.0012)^{6}$ & $-0.0018(0.0012)^{6}$ & $-0.0018(0.0012)^{6}$ \\
\hline AIC & 123.159 & 118.431 & 120.740 \\
\hline \multicolumn{4}{|c|}{ Variation between source continent } \\
\hline From Africa & $0.0519(0.0599)$ & $0.0487(0.0577)$ & $0.0422(0.0570)$ \\
\hline From Eurasia & $0.1287(0.0260)$ & $0.1226(0.0260)$ & $0.1185(0.0253)$ \\
\hline From North America & $0.0386(0.0331)$ & $0.0303(0.0330)$ & $0.0240(0.0329)$ \\
\hline From South America & $0.1052(0.1528)$ & $0.1002(0.1439)$ & $0.0980(0.1407)$ \\
\hline AIC & 121.666 & 115.841 & 114.379 \\
\hline \multicolumn{4}{|c|}{ Variation between target continent } \\
\hline To Africa & $0.1191(0.0374)$ & $0.1160(0.0373)$ & $0.1137(0.0366)$ \\
\hline To Eurasia & $0.0488(0.0340)$ & $0.0453(0.0343)$ & $0.0379(0.0337)$ \\
\hline To North America & $0.1351(0.0356)$ & $0.1260(0.0360)$ & $0.1214(0.0346)$ \\
\hline To South America & $0.0192(0.0513)$ & $0.0017(0.0503)$ & $-0.0009(0.0495)$ \\
\hline AIC & 121.745 & 114.352 & 114.924 \\
\hline \multicolumn{4}{|c|}{ Variation between source and target continent } \\
\hline Africa to Eurasia & $0.0519(0.0600)$ & $0.0487(0.0577)$ & $0.0422(0.0570)$ \\
\hline Eurasia to Africa & $0.1191(0.0374)$ & $0.1161(0.0373)$ & $0.1137(0.0366)$ \\
\hline Eurasia to North America & $0.1372(0.0368)$ & $0.1281(0.0370)$ & $0.1231(0.0357)$ \\
\hline North America to Eurasia & $0.0479(0.0420)$ & $0.0439(0.0428)$ & $0.0362(0.0429)$ \\
\hline North to South America & $0.0192(0.0513)$ & $0.0018(0.0503)$ & $-0.0009(0.0496)$ \\
\hline South to North America & $0.1051(0.1529)$ & $0.1002(0.1439)$ & $0.098(0.1407)$ \\
\hline AIC & 124.174 & 116.893 & 117.311 \\
\hline
\end{tabular}


Table S2: Global pre-dispersal success.

The test statistic is the logarithm of the ratio between the diversification rate at the time of dispersal of dispersers and the median of the diversification rates of all species alive globally just before the dispersal event (see Fig. 1).

The p-values for global rate and for the temporal age effect are the probability of being different from 0 . For models with different patterns depending on the source and/ or target continent, the p-value is based on the probability of being different from the estimated global rate.

\begin{tabular}{|c|c|c|c|}
\hline & $\begin{array}{l}\text { 1.0-million-year } \\
\text { intervals }\end{array}$ & $\begin{array}{l}0.5 \text {-million-year } \\
\text { intervals }\end{array}$ & $\begin{array}{l}0.25 \text {-million-year } \\
\text { intervals }\end{array}$ \\
\hline \multicolumn{4}{|c|}{ Simplest model } \\
\hline Global & $0.1295(0.0212)^{* * *}$ & $0.1205(0.0205)^{* * *}$ & $0.1142(0.0206)^{* * *}$ \\
\hline AIC & 150.586 & 159.119 & 159.394 \\
\hline \multicolumn{4}{|c|}{ Temporal variation } \\
\hline Global & $0.1757(0.0271)^{* * *}$ & $0.1636(0.0272)^{* * *}$ & $0.1562(0.0271)^{* * * *}$ \\
\hline Age & $-0.0029(0.0013)^{*}$ & $-0.0027(0.0013)^{*}$ & $-0.0026(0.0013)$ \\
\hline AIC & 141.937 & 152.941 & 147.405 \\
\hline \multicolumn{4}{|c|}{ Variation between source continent } \\
\hline From Africa & $0.1101(0.0651)$ & $0.1010(0.0612)$ & $0.940(0.0631)$ \\
\hline From Eurasia & $0.1516(0.0266)$ & $0.1455(0.0267)$ & $0.1414(0.0266)$ \\
\hline From North America & $0.1005(0.0355)$ & $0.0863(0.0353)$ & $0.0759(0.0353)$ \\
\hline From South America & $0.0892(0.1428)$ & $0.1119(0.1442)$ & $0.1122(0.1416)$ \\
\hline AIC & 153.595 & 159.794 & 156.610 \\
\hline \multicolumn{4}{|c|}{ Variation between target continent } \\
\hline To Africa & $0.1476(0.0368)$ & $0.1468(0.0372)$ & $0.1443(0.0371)$ \\
\hline To Eurasia & $0.1131(0.0373)$ & $0.1050(0.0362)$ & $0.0959(0.0369)$ \\
\hline To North America & $0.1508(0.0369)$ & $0.1420(0.0370)$ & $0.1373(0.0358)$ \\
\hline To South America & $0.0710(0.0528)$ & $0.0423(0.0528)$ & $0.0324(0.0526)$ \\
\hline AIC & 154.452 & 158.814 & 157.279 \\
\hline \multicolumn{4}{|c|}{ Variation between source and target continent } \\
\hline Africa to Eurasia & $0.1100(0.0651)$ & $0.1009(0.0612)$ & $0.0941(0.0631)$ \\
\hline Eurasia to Africa & $0.1476(0.0368)$ & $0.1468(0.0372)$ & $0.1443(0.0371)$ \\
\hline Eurasia to North America & $0.1550(0.0383)$ & $0.1440(0.0385)$ & $0.1391(0.0375)$ \\
\hline North America to Eurasia & $0.1151(0.0446)$ & $0.1077(0.0443)$ & $0.0972(0.0449)$ \\
\hline North to South America & $0.0710(0.0528)$ & $0.0443(0.0529)$ & $0.0324(0.0527)$ \\
\hline South to North America & $0.0892(0.1418)$ & $0.1119(0.1442)$ & $0.1124(0.1415)$ \\
\hline AIC & 156.490 & 161.911 & 159.934 \\
\hline
\end{tabular}




\section{Table S3: Continental pre-dispersal success in simulations.}

Values are given for both the full simulated tree and the simulated incomplete sampling. The difference is the median difference between estimates for each tree. In parentheses, we list the number of times where this difference is negative (i.e. how many times the value is larger for incomplete sampling than the full tree).

The test statistic is the logarithm of the ratio between the diversification rate at the time of dispersal of dispersers and the median of the diversification rates of all species in the source continent from just before the dispersal event (see Fig. 1).

For models with different patterns based on the source and/ or target continent, the p-value is based on the probability of being different from the estimated global rate. The p-value for the difference is based on a two-tailed binomial distribution and tests if incomplete sampling is equally likely to lead to larger and smaller values than complete sampling.

\begin{tabular}{|c|c|c|c|}
\hline & Full tree & $\begin{array}{l}\text { Incomplete } \\
\text { sampling }\end{array}$ & Difference \\
\hline \multicolumn{4}{|c|}{ Simplest model } \\
\hline Global & $0.0192(0.0149)$ & $0.0207(0.0167)$ & $-1.75 \times 10^{-3}(57 / 100)$ \\
\hline AIC & 146.691 & 126.717 & \\
\hline \multicolumn{4}{|c|}{ Temporal variation } \\
\hline Global & $0.0288(0.0233)$ & $0.0316(0.0256)$ & $-1.75 \times 10^{-3}(57 / 100)$ \\
\hline Age & $-0.0007(0.0010)$ & $-0.0008(0.0012)$ & $1.18 \times 10^{-4}(43 / 100)$ \\
\hline AIC & 146.503 & 125.441 & \\
\hline \multicolumn{4}{|c|}{ Variation between source continent } \\
\hline From Africa & NA & NA & NA \\
\hline From Eurasia & $0.0182(0.0307)$ & $0.0201(0.0367)$ & $-6.06 \times 10^{-3}(61 / 100)^{*}$ \\
\hline From North America & $0.0159(0.0194)$ & $0.0161(0.0204)$ & $-7.62 \times 10^{-5}(50 / 100)$ \\
\hline From South America & $0.0352(0.0377)$ & $0.0450(0.0451)$ & $-1.15 \times 10^{-2}(66 / 100)^{* *}$ \\
\hline AIC & 148.964 & 129.271 & \\
\hline \multicolumn{4}{|c|}{ Variation between target continent } \\
\hline To Africa & $-0.0019(0.0560)$ & $-0.0007(0.0592)$ & $1.91 \times 10^{-3}(47 / 100)$ \\
\hline To Eurasia & $0.0323(0.0283)$ & $0.0339(0.0282)$ & $-1.88 \times 10^{-3}(54 / 100)$ \\
\hline To North America & $0.0293(0.0257)$ & $0.0376(0.0310)$ & $-7.93 \times 10^{-3}(61 / 100)^{*}$ \\
\hline To South America & $-0.0020(0.0286)$ & $-0.0035(0.0291)$ & $2.30 \times 10^{-3}(47 / 100)$ \\
\hline AIC & 146.629 & 127.837 & \\
\hline \multicolumn{4}{|c|}{ Variation between source and target continent } \\
\hline Africa to Eurasia & NA & NA & NA \\
\hline Eurasia to Africa & $-0.0019(0.0560)$ & $-0.0070(0.0592)$ & $1.91 \times 10^{-3}(47 / 100)$ \\
\hline Eurasia to North America & $0.0238(0.0362)$ & $0.0313(0.0437)$ & $-8.36 \times 10^{-3}(60 / 100)^{6}$ \\
\hline North America to Eurasia & $0.0323(0.0283)$ & $0.0338(0.0282)$ & $-1.88 \times 10^{-3}(54 / 100)$ \\
\hline North to South America & $-0.0020(0.0286)$ & $-0.0035(0.0291)$ & $2.30 \times 10^{-3}(47 / 100)$ \\
\hline South to North America & $0.0352(0.0377)$ & $0.0450(0.0451)$ & $-1.15 \times 10^{-2}(66 / 100)^{* *}$ \\
\hline AIC & 148.457 & 129.797 & \\
\hline
\end{tabular}




\section{Table S4: Global pre-dispersal success in simulations.}

1217 Values are given for both the full simulated tree and the simulated incomplete sampling. The difference is the median difference between estimates for each tree. In parentheses, we list the number of times where this difference is negative (i.e. how many times the value is larger for incomplete sampling than the full tree).

The test statistic is the logarithm of the ratio between the diversification rate at the time of dispersal of dispersers and the median diversification rates of all species alive globally just before the dispersal event (see Fig. 1).

For models with different patterns based on the source and/ or target continent, the p-value is based on the probability of being different from the estimated global rate. The p-value for the difference is based on a two-tailed binomial distribution and tests if incomplete sampling is equally likely to lead to larger and smaller values than complete sampling.

\begin{tabular}{|c|c|c|c|}
\hline & Full tree & $\begin{array}{l}\text { Incomplete } \\
\text { sampling }\end{array}$ & Difference \\
\hline \multicolumn{4}{|c|}{ Simplest model } \\
\hline Global & $0.0192(0.0149)$ & $0.0207(0.0167)$ & $-1.75 \times 10^{-3}(57 / 100)$ \\
\hline AIC & 146.691 & 126.717 & \\
\hline \multicolumn{4}{|c|}{ Temporal variation } \\
\hline Global & $0.0288(0.0233)$ & $0.0316(0.0256)$ & $-1.75 \times 10^{-3}(57 / 100)$ \\
\hline Age & $-0.0007(0.0010)$ & $-0.0008(0.0012)$ & $1.18 \times 10^{-4}(43 / 100)$ \\
\hline AIC & 146.503 & 125.441 & \\
\hline \multicolumn{4}{|c|}{ Variation between source continent } \\
\hline From Africa & NA & NA & NA \\
\hline From Eurasia & $0.0182(0.0307)$ & $0.0201(0.0367)$ & $-6.06 \times 10^{-3}(61 / 100)^{*}$ \\
\hline From North America & $0.0159(0.0194)$ & $0.0161(0.0204)$ & $-7.62 \times 10^{-5}(50 / 100)$ \\
\hline From South America & $0.0352(0.0377)$ & $0.0450(0.0451)$ & $-1.15 \times 10^{-2}(66 / 100)^{* *}$ \\
\hline AIC & 148.964 & 129.271 & \\
\hline \multicolumn{4}{|c|}{ Variation between target continent } \\
\hline To Africa & $-0.0019(0.0560)$ & $-0.0007(0.0592)$ & $1.91 \times 10^{-3}(47 / 100)$ \\
\hline To Eurasia & $0.0323(0.0283)$ & $0.0339(0.0282)$ & $-1.88 \times 10^{-3}(54 / 100)$ \\
\hline To North America & $0.0293(0.0257)$ & $0.0376(0.0310)$ & $-7.93 \times 10^{-3}(61 / 100)^{*}$ \\
\hline To South America & $-0.0020(0.0286)$ & $-0.0035(0.0291)$ & $2.30 \times 10^{-3}(47 / 100)$ \\
\hline AIC & 146.629 & 127.837 & \\
\hline \multicolumn{4}{|c|}{ Variation between source and target continent } \\
\hline Africa to Eurasia & NA & NA & NA \\
\hline Eurasia to Africa & $-0.0019(0.0560)$ & $-0.0070(0.0592)$ & $1.91 \times 10^{-3}(47 / 100)$ \\
\hline Eurasia to North America & $0.0238(0.0362)$ & $0.0313(0.0437)$ & $-8.36 \times 10^{-3}(60 / 100)^{6}$ \\
\hline North America to Eurasia & $0.0323(0.0283)$ & $0.0338(0.0282)$ & $-1.88 \times 10^{-3}(54 / 100)$ \\
\hline North to South America & $-0.0020(0.0286)$ & $-0.0035(0.0291)$ & $2.30 \times 10^{-3}(47 / 100)$ \\
\hline South to North America & $0.0352(0.0377)$ & $0.0450(0.0451)$ & $-1.15 \times 10^{-2}(66 / 100)^{* *}$ \\
\hline AIC & 148.457 & 129.797 & \\
\hline
\end{tabular}




\begin{tabular}{|c|c|c|c|c|c|c|c|c|c|}
\hline & \multicolumn{3}{|c|}{3 Million years } & \multicolumn{3}{|c|}{5 Million years } & \multicolumn{3}{|c|}{7 Million years } \\
\hline & $\begin{array}{l}\text { 1.0-million-year } \\
\text { intervals }\end{array}$ & $\begin{array}{l}0.5 \text {-million-year } \\
\text { intervals }\end{array}$ & $\begin{array}{l}0.25 \text {-million-year } \\
\text { intervals }\end{array}$ & $\begin{array}{l}\text { 1.0-million-year } \\
\text { intervals }\end{array}$ & $\begin{array}{l}0.5 \text {-million-year } \\
\text { intervals }\end{array}$ & $\begin{array}{l}0.25 \text {-million-year } \\
\text { intervals }\end{array}$ & $\begin{array}{l}\text { 1.0-million-year } \\
\text { intervals }\end{array}$ & $\begin{array}{l}0.5 \text {-million-year } \\
\text { intervals }\end{array}$ & $\begin{array}{l}0.25 \text {-million-year } \\
\text { intervals }\end{array}$ \\
\hline \multicolumn{10}{|c|}{ Simplest model } \\
\hline Global & $1.5463(0.0455)^{* * * *}$ & $1.4808(0.0495)^{* * * *}$ & $1.4500(0.0520)^{* * * *}$ & $1.5401(0.0693)^{* * *}$ & $1.4606(0.0730)^{* * *}$ & $1.4182(0.0741)^{* * * *}$ & $1.4846(0.0928)^{* * * *}$ & $1.3909(0.0939)^{* * * *}$ & $1.3423(0.0942)^{* * *}$ \\
\hline AIC & 558.620 & 571.858 & 574.258 & 646.651 & 644.155 & 642.460 & 700.557 & 685.244 & 679.522 \\
\hline \multicolumn{10}{|c|}{ Temporal variation } \\
\hline Global & $1.5167(0.0455)^{* * * *}$ & $1.4427(0.0732)^{* * * *}$ & $1.4109(0.0762)^{* * * *}$ & $1.5695(0.0993)^{* * *}$ & $1.4782(0.1049)^{* * * *}$ & $1.4301(0.1090)^{* * * *}$ & $1.5224(0.1441)^{* * * *}$ & $1.4120(0.1489)^{* * *}$ & $1.3600(0.1492)^{*}$ \\
\hline Age & $0.0016(0.0033)$ & $0.0022(0.0037)$ & $0.0022(0.0038)$ & $-0.0012(0.0046)$ & $-0.0006(0.0048)$ & $-0.0004(0.0050)$ & $-0.0017(0.0056)$ & $-0.0009(0.0058)$ & $-0.0008(0.0057)$ \\
\hline AIC & 557.176 & 572.007 & 573.035 & 647.353 & 645.788 & 643.953 & 701.968 & 686.662 & 681.166 \\
\hline \multicolumn{10}{|c|}{ Variation between source continent } \\
\hline From Africa & $1.4552(0.1200)$ & $1.3819(0.1248)$ & $1.3411(0.1318)$ & $1.4119(0.1694)$ & $1.3555(0.1778)$ & $1.3133(0.1844)$ & $1.3539(0.2250)$ & $1.2732(0.2314)$ & $1.2362(0.2336)$ \\
\hline From Eurasia & $1.5800(0.0577)$ & $1.5106(0.0624)$ & $1.4763(0.0648)$ & $1.5725(0.0837)$ & $1.4938(0.0877)$ & $1.4487(0.0890)$ & $1.5377(0.1155)$ & $1.4492(0.1192)$ & $1.3973(0.1210)$ \\
\hline From North & $1.5275(0.0794)$ & $1.4727(0.0894)$ & $1.4501(0.0944)$ & $1.5318(0.1240)$ & $1.4467(0.1314)$ & $1.4056(0.1315)$ & $1.4459(0.1569)$ & $1.3431(0.1600)$ & $1.2938(0.1613)$ \\
\hline America & & & & & & & & & \\
\hline AIC & 555.792 & 569.375 & 572.882 & 647.004 & 645.084 & 645.226 & 703.163 & 687.947 & 682.634 \\
\hline \multicolumn{10}{|c|}{ Variation between target continent } \\
\hline To Africa & $1.5264(0.0862)$ & $1.4464(0.0885)$ & $1.4090(0.0912)$ & $1.4806(0.1152)$ & $1.3990(0.1184)$ & $1.3565(0.1203)$ & $1.4580(0.1538)$ & $1.3993(0.1583)$ & $1.3650(0.1613)$ \\
\hline To Eurasia & $1.5405(0.0772)$ & $1.4700(0.0838)$ & $1.4383(0.0893)$ & $1.5037(0.1131)$ & $1.4262(0.1183)$ & $1.3857(0.1203)$ & $1.4274(0.1447)$ & $1.3312(0.1475)$ & $1.2839(0.1490)$ \\
\hline To North America & $1.6248(0.0810)$ & $1.5622(0.0851)$ & $1.5306(0.0885)$ & $1.6591(0.1234)$ & $1.5781(0.1241)$ & $1.5358(0.1255)$ & $1.5990(0.1588)$ & $1.4831(0.1614)$ & $1.4171(0.1631)$ \\
\hline To South America & $1.3749(0.1507)$ & $1.3526(0.1628)$ & $1.3460(0.1678)$ & $1.5047(0.2702)$ & $1.4004(0.2834)$ & $1.3456(0.2821)$ & $1.3713(0.3859)$ & $1.2702(0.3997)$ & $1.2446(0.4160)$ \\
\hline AIC & 556.521 & 570.46 & 575.529 & 645.487 & 644.715 & 645.327 & 704.990 & 690.138 & 683.700 \\
\hline \multicolumn{10}{|c|}{ Variation between source and target continent } \\
\hline Africa to Eurasia & $1.4554(0.1196)$ & $1.3819(0.1245)$ & $1.3411(0.1315)$ & $1.4219(0.1691)$ & $1.3557(0.1777)$ & $1.3132(0.1842)$ & $1.3538(0.2251)$ & $1.2731(0.2316)$ & $1.2362(0.2340)$ \\
\hline Eurasia to Africa & $1.5264(0.0862)$ & $1.4464(0.0885)$ & $1.4091(0.0912)$ & $1.4806(0.1152)$ & $1.3991(0.1184)$ & $1.3565(0.1203)$ & $1.4579(0.1540)$ & $1.3993(0.1583)$ & $1.3649(0.1614)$ \\
\hline $\begin{array}{l}\text { Eurasia to North } \\
\text { America }\end{array}$ & $1.6284(0.0814)$ & $1.5675(0.0857)$ & $1.5368(0.0893)$ & $1.6573(0.1233)$ & $1.5767(0.1243)$ & $1.5312(0.1257)$ & $1.5989(0.1590)$ & $1.4827(0.1616)$ & $1.4167(0.1634)$ \\
\hline $\begin{array}{l}\text { North America to } \\
\text { Eurasia }\end{array}$ & $1.5829(0.0945)$ & $1.5122(0.1043)$ & $1.4842(0.1108)$ & $1.5392(0.1355)$ & $1.4572(0.1428)$ & $1.4178(0.1431)$ & $1.4570(0.1707)$ & $1.3539(0.1735)$ & $1.3011(0.1732)$ \\
\hline $\begin{array}{l}\text { North to South } \\
\text { America }\end{array}$ & $1.3748(0.1507)$ & $1.3527(0.1627)$ & $1.3460(0.1678)$ & $1.5046(0.2702)$ & $1.4005(0.2835)$ & $1.3458(0.2822)$ & $1.3714(0.3862$ & $1.2700(0.4001)$ & $1.2447(0.4164)$ \\
\hline AIC & 552.733 & 568.98 & 568.980 & 645.240 & 645.840 & 646.678 & 706.231 & 690.988 & 685.240 \\
\hline
\end{tabular}


Table S6: Continental post-dispersal success.

The test statistic is the square root of the mean number of species alive after a given number of million years $(3,5$ or 7$)$ after dispersal, divided by the mean for species in the target continent. Significance for the estimate is the probability of being different from 1 (the random expectation), for age it is the probability of being different from 0 and for models with different patterns based on target and/ or source continent it is based on the probability of being different from the estimated global rate.

\begin{tabular}{|c|c|c|c|c|c|c|c|c|c|}
\hline & \multicolumn{3}{|c|}{3 Million years } & \multicolumn{3}{|c|}{5 Million years } & \multicolumn{3}{|c|}{7 Million years } \\
\hline & $\begin{array}{l}\text { 1.0-million-year } \\
\text { intervals }\end{array}$ & $\begin{array}{l}0.5 \text {-million-year } \\
\text { intervals }\end{array}$ & $\begin{array}{l}0.25 \text {-million-year } \\
\text { intervals }\end{array}$ & $\begin{array}{l}\text { 1.0-million-year } \\
\text { intervals }\end{array}$ & $\begin{array}{l}0.5 \text {-million-year } \\
\text { intervals }\end{array}$ & $\begin{array}{l}0.25 \text {-million-year } \\
\text { intervals }\end{array}$ & $\begin{array}{l}\text { 1.0-million-year } \\
\text { intervals }\end{array}$ & $\begin{array}{l}0.5 \text {-million-year } \\
\text { intervals }\end{array}$ & $\begin{array}{l}0.25 \text {-million-year } \\
\text { intervals }\end{array}$ \\
\hline \multicolumn{10}{|c|}{ Simplest model } \\
\hline $\begin{array}{l}\text { Global } \\
\text { AIC }\end{array}$ & $\begin{array}{l}1.5321(0.0463)^{* * * *} \\
564.200\end{array}$ & $\begin{array}{l}1.4666(0.0494)^{* * * *} \\
570.942\end{array}$ & $\begin{array}{l}1.4361(0.0517)^{* * * *} \\
572.367\end{array}$ & $\begin{array}{l}1.5197(0.0699)^{* * * *} \\
644.765\end{array}$ & $\begin{array}{l}1.4433(0.0730)^{* * *} \\
638.300\end{array}$ & $\begin{array}{l}1.4018(0.0739)^{* * * *} \\
642.178\end{array}$ & $\begin{array}{l}1.4622(0.0952)^{* * * *} \\
697.054\end{array}$ & $\begin{array}{l}1.3695(0.0956)^{* * * *} \\
677.991\end{array}$ & $\begin{array}{l}1.3203(0.0953)^{*} \\
671.446\end{array}$ \\
\hline \multicolumn{10}{|c|}{ Temporal variation } \\
\hline Global & $1.4876(0.0679)^{* * * 4}$ & $1.4089(0.0734)^{* * * *}$ & $1.3775(0.0761)^{* * * *}$ & $1.5430(0.1023)^{* * *}$ & $1.4554(0.1066)^{* * * *}$ & $1.4093(0.1090)^{* * * *}$ & $1.5087(0.1477)^{* * * *}$ & $1.4004(0.1509)^{* * *}$ & $1.3468(0.1485)^{*}$ \\
\hline Age & $0.0025(0.0033)$ & $0.0031(0.0037)$ & $0.0032(0.0039)$ & $-0.0008(0.0048)$ & $-0.0004(0.0050)$ & $-0.0002(0.0051)$ & $-0.0020(0.0058)$ & $-0.0013(0.0060)$ & $-0.0012(0.0059)$ \\
\hline AIC & 564.603 & 569.47 & 568.672 & 644.363 & 638.872 & 642.141 & 696.491 & 679.063 & 671.775 \\
\hline \multicolumn{10}{|c|}{ Variation between source continent } \\
\hline From Africa & $1.4041(0.1199)$ & $1.3302(0.1234)$ & $1.2907(0.1303)$ & $1.3310(0.1674)$ & $1.2666(0.1741)$ & $1.2263(0.1800)$ & $1.2344(0.2187)$ & $1.1587(0.2241)$ & $1.1230(0.2282)$ \\
\hline From Eurasia & $1.6068(0.0603)$ & $1.5322(0.0643)$ & $1.4957(0.0668)$ & $1.6058(0.0888)$ & $1.5246(0.0912)$ & $1.4784(0.0922)$ & $1.5818(0.1227)$ & $1.4863(0.1263)$ & $1.4311(0.1267)$ \\
\hline $\begin{array}{l}\text { From North } \\
\text { America }\end{array}$ & $1.4560(0.0832)$ & $1.4130(0.0917)$ & $1.3945(0.0966)$ & $1.4491(0.1272)$ & $1.3791(0.1362)$ & $1.3405(0.1370)$ & $1.3552(0.1654)$ & $1.2684(0.1682)$ & $1.2211(0.1699)$ \\
\hline AIC & 556.673 & 563.667 & 566.153 & 643.753 & 638.831 & 640.397 & 693.680 & 676.812 & 668.212 \\
\hline \multicolumn{10}{|c|}{ Variation between target continent } \\
\hline To Africa & $1.5341(0.0895)$ & $1.4484(0.0915)$ & $1.4088(0.0938)$ & $1.4465(0.1199)$ & $1.3607(0.1207)$ & $1.3171(0.1210)$ & $1.3871(0.1569)$ & $1.3221(0.1607)$ & $1.2858(0.1623)$ \\
\hline To Eurasia & $1.5136(0.0785)$ & $1.4472(0.0850)$ & $1.4160(0.0911)$ & $1.4491(0.1161)$ & $1.3761(0.1232)$ & $1.3360(0.1248)$ & $1.3552(0.1516)$ & $1.2667(0.1541)$ & $1.2212(0.1569)$ \\
\hline To North America & $1.6714(0.0839)^{\circ}$ & $1.6016(0.0879)$ & $1.5681(0.0916)$ & $1.7535(0.1287)^{\prime}$ & $1.6694(0.1278)^{\circ}$ & $1.6222(0.1303)^{6}$ & $1.7334(0.1690)^{\prime}$ & $1.6065(0.1723)$ & $1.5354(0.1730)$ \\
\hline To South America & $1.1418(0.1472)^{* * *}$ & $1.1366(0.1643)^{*}$ & $1.1379(0.1695)^{*}$ & $1.1965(0.2684)$ & $1.1262(0.2927)$ & $1.0809(0.2894)$ & $0.9792(0.3900)$ & $0.9267(0.4108)$ & $0.9016(0.4124)$ \\
\hline AIC & 550.297 & 562.453 & 563.308 & 635.087 & 632.828 & 635.919 & 690.538 & 676.756 & 666.862 \\
\hline \multicolumn{10}{|c|}{ Variation between source and target continent } \\
\hline Africa to Eurasia & $1.4042(0.1183)$ & $1.3303(0.1222)$ & $1.2907(0.1292)$ & $1.3311(0.1658)$ & $1.2666(0.1727)$ & $1.2263(0.1787)$ & $1.2345(0.2171)$ & $1.1588(0.2232)$ & $1.1231(0.2276)$ \\
\hline Eurasia to Africa & $1.5341(0.0894)$ & $1.4484(0.0914)$ & $1.4089(0.0936)$ & $1.4466(0.1198)$ & $1.3607(0.1206)$ & $1.3171(0.1208)$ & $1.3871(0.1568)$ & $1.3220(0.1607)$ & $1.2857(0.1624)$ \\
\hline $\begin{array}{l}\text { Eurasia to North } \\
\text { America }\end{array}$ & $1.6724(0.0843)^{\prime}$ & $1.6055(0.0884)$ & $1.5729(0.0922)$ & $1.7514(0.1285)^{6}$ & $1.6677(0.1282)^{\prime}$ & $1.6212(0.1308)$ & $1.7333(0.1690)^{\prime}$ & $1.6061(0.1724)$ & $1.5351(0.1732)$ \\
\hline $\begin{array}{l}\text { North America to } \\
\text { Eurasia }\end{array}$ & $1.5677(0.0971)$ & $1.5029(0.1055)$ & $1.4753(0.1130)$ & $1.5002(0.1395)$ & $1.4238(0.1487)$ & $1.3847(0.1483)$ & $1.4048(0.1791)$ & $1.3101(0.1824)$ & $1.2581(0.1827)$ \\
\hline $\begin{array}{l}\text { North to South } \\
\text { America }\end{array}$ & $1.1420(0.1470)^{* *}$ & $1.1366(0.1641)^{*}$ & $1.1379(0.1692)^{*}$ & $1.1966(0.2682)$ & $1.1263(0.2925)$ & $1.0810(0.2892)$ & $0.9793(0.3897)$ & $0.9268(0.4108)$ & $0.9014(0.4126)$ \\
\hline AIC & 546.753 & 557.481 & 559.768 & 634.213 & 632.508 & 634.331 & 691.426 & 678.12 & 667.401 \\
\hline
\end{tabular}


Table S7: Post-dispersal success in simulations.

The test statistic is the square root of the mean number of species alive after 5 million years after dispersal divided by the mean value for all other species globally. Significance for the estimate is the probability of being different from 1 (the random expectation), for age it is the probability of being different from 0 and for models with different patterns based on the source and/ or target continent it is based on the probability of being different from the estimated global rate.

Values are given for both the full simulated tree and the simulated incomplete sampling. The difference is the median difference between estimates for each tree. In parentheses, we list the number of times where this difference is negative (i.e. how many times the value is larger for incomplete sampling than the full tree). The p-value for the difference is based on a two-tailed binomial distribution and tests if incomplete sampling is equally likely to lead to larger and smaller values than complete sampling.

\begin{tabular}{|c|c|c|c|c|c|c|}
\hline & \multicolumn{3}{|c|}{ Global post-dispersal success } & \multicolumn{3}{|c|}{ Continental post-dispersal success } \\
\hline & Full tree & Incomplete sampling & Difference & Full tree & Incomplete sampling & Difference \\
\hline \multicolumn{7}{|c|}{ Simplest model } \\
\hline Global & $1.0696(0.0816)$ & $1.0734(0.0929)$ & $-6.33 \times 10^{-4}(52 / 100)$ & $1.1226(0.726)$ & $1.1591(0.0809)$ & $-3.46 \times 10^{-2}(77 / 100)^{* * * *}$ \\
\hline AIC & 1252.351 & 973.833 & & 1251.687 & 998.474 & \\
\hline \multicolumn{7}{|c|}{ Temporal variation } \\
\hline Global & $1.0698(0.1158)$ & $1.0755(0.1190)$ & $5.36 \times 10^{-3}(47 / 100)$ & $1.1317(0.1105)$ & $1.1614(0.1259)$ & $-2.39 \times 10^{-2}(67 / 100)^{* * *}$ \\
\hline Age & $-0.0001(0.0038)$ & $-0.0003(0.0045)$ & $5.54 \times 10^{-5}(50 / 100)$ & $-0.0004(0.0040)$ & $-0.0004(0.0049)$ & $-4.08 \times 10^{-4}(57 / 100)$ \\
\hline AIC & 1253.484 & 974.824 & & 1252.211 & 998.50 & \\
\hline \multicolumn{7}{|c|}{ Variation between source continent } \\
\hline From Africa & NA & NA & NA & NA & NA & NA \\
\hline From Eurasia & $1.0787(0.1277)$ & $1.0734(0.1725)$ & $6.90 \times 10^{-3}(41 / 100)^{6}$ & $1.1020(0.1321)$ & $1.0951(0.1701)$ & $1.20 \times 10^{-2}(42 / 100)$ \\
\hline From North America & $1.0604(0.0941)$ & $1.0669(0.1025)$ & $-1.67 \times 10^{-3}(51 / 100)$ & $1.1589(0.0924)$ & $1.2094(0.1043)$ & $-4.54 \times 10^{-2}(51 / 100)$ \\
\hline From South America & $1.0806(0.1543)$ & $1.1042(0.1765)$ & $-2.23 \times 10^{-2}(59 / 100)^{6}$ & $1.0148(0.1597)$ & $1.0258(0.1791)$ & $-7.86 \times 10^{-3}(58 / 100)$ \\
\hline AIC & 1254.421 & 973.611 & & 1252.495 & 995.151 & \\
\hline \multicolumn{7}{|c|}{ Variation between target continent } \\
\hline To Africa & $0.7306(0.2327)$ & $0.7528(0.2874)$ & $-9.21 \times 10^{-3}(52 / 100)$ & $0.9970(0.2512)$ & $1.0127(0.3101)$ & $1.66 \times 10^{-2}(47 / 100)$ \\
\hline To Eurasia & $1.0966(0.1210)$ & $1.0825(0.1236)$ & $1.84 \times 10^{-2}(37 / 100)^{*}$ & $1.1913(0.1198)$ & $1.2262(0.1444)$ & $-3.71 \times 10^{-2}(63 / 100)^{*}$ \\
\hline To North America & $1.1493(0.1153)$ & $1.1567(0.1329)$ & $-3.02 \times 10^{-3}(51 / 100)$ & $1.0794(0.1236)$ & $1.0766(0.1397)$ & $4.64 \times 10^{-3}(48 / 100)$ \\
\hline To South America & $1.0266(0.1238)$ & $1.0477(0.1291)$ & $-1.64 \times 10^{-2}(62 / 100)^{*}$ & $1.1297(0.1273)$ & $1.1822(0.1247)$ & $-4.25 \times 10^{-2}(68 / 100)^{* * *}$ \\
\hline AIC & 1240.512 & 967.294 & & 1253.755 & 991.077 & \\
\hline \multicolumn{7}{|c|}{ Variation between source and target continent } \\
\hline Africa to Eurasia & NA & NA & NA & NA & NA & \\
\hline Eurasia to Africa & $0.7305(0.2326)$ & $0.7528(0.2875)$ & $-9.21 \times 10^{-3}(52 / 100)$ & $0.9970(0.2512)$ & $1.0124(0.3100)$ & $1.66 \times 10^{-2}(47 / 100)$ \\
\hline Eurasia to North America & $1.2061(0.1433)$ & $1.2085(0.1793)$ & $3.91 \times 10^{-3}(48 / 100)$ & $1.1325(0.1494)$ & $1.1219(0.1842)$ & $1.42 \times 10^{-2}(42 / 100)$ \\
\hline North America to Eurasia & $1.0966(0.1209)$ & $1.0825(0.1236)$ & $1.84 \times 10^{-2}(37 / 100)^{*}$ & $1.1913(0.1198)$ & $1.2262(0.1445)$ & $-3.71 \times 10^{-2}(63 / 100)^{*}$ \\
\hline North to South America & $1.0267(0.1238)$ & $1.0477(0.1291)$ & $-1.64 \times 10^{-2}(62 / 100)^{*}$ & $1.1297(0.1273)$ & $1.1823(0.1246)$ & $-4.25 \times 10^{-2}(68 / 100)^{* * * *}$ \\
\hline South to North America & $1.0806(0.1537)$ & $1.1042(0.1759)$ & $-2.23 \times 10^{-2}(59 / 100)^{6}$ & $1.0148(0.1596)$ & $1.0257(0.1790)$ & $-7.86 \times 10^{-3}(58 / 100)$ \\
\hline AIC & 1238.486 & 967.047 & & 1254.992 & 991.629 & \\
\hline
\end{tabular}


Table S8: Additional species not in NOW or PBDB.

\begin{tabular}{|c|c|c|c|}
\hline Family & Genus & Species & Reference \\
\hline Amphicynodontinae & Amphicynodon & brachyrostris & 64 \\
\hline Amphicynodontinae & Amphicynodon & cephalogalinus & 64 \\
\hline Amphicynodontinae & Amphicynodon & chardini & 64 \\
\hline Amphicynodontinae & Amphicynodon & crassirostris & 64 \\
\hline Amphicynodontinae & Nothocyon & geismarianus & 65 \\
\hline Amphicyonidae & Askazansoria & mavrini & 66 \\
\hline Amphicyonidae & Haplocyonoides & suevicus & 67 \\
\hline Amphicyonidae & Haplocyonopsis & crassidens & 67 \\
\hline Amphicyonidae & Janvierocyon & pontignensis & 68 \\
\hline Amphicyonidae & Temnocyon & ferox & 69 \\
\hline Amphicyonidae & Vishnucyon & chinjiensis & 70 \\
\hline Barbourofelidae & Afrosmilus & turkanae & 56 \\
\hline Barbourofelidae & Vampyrictis & vipera & 56 \\
\hline Basal Pinnipedia & Puijila & darwini & 71 \\
\hline Canidae & Nyctereutes & terblanchei & 56 \\
\hline Canidae & Vulpes & skinneri & 72 \\
\hline Felidae & Asilifelis & coteae & 73 \\
\hline Felidae & Proailurus & bournonnensis & 74 \\
\hline Felidae & Proailurus & major & 74 \\
\hline Felidae & Styriofelis & vallesiensis & 75 \\
\hline Felidae & Yoshi & garevskii & 76 \\
\hline Herpestidae & Herpestes & debilis & 56 \\
\hline Herpestidae & Herpestides & aequatorialis & 56 \\
\hline Herpestidae & Leptoplesictis & mbitensis & 56 \\
\hline Herpestidae & Leptoplesictis & rangwai & 56 \\
\hline Herpestidae & Suricata & major & 56 \\
\hline Hyaenodontidae & Alienetherium & buxwilleri & 77 \\
\hline Hyaenodontidae & Allopterodon & bulbosus & 77 \\
\hline Hyaenodontidae & Allopterodon & minor & 77 \\
\hline Hyaenodontidae & Cynohyaenodon & cailuxy & 77 \\
\hline Hyaenodontidae & Cynohyaenodon & lautricensis & 77 \\
\hline Hyaenodontidae & Cynohyaenodon & ruetimeyeri & 77 \\
\hline Hyaenodontidae & Cynohyaenodon & trux & 77 \\
\hline Hyaenodontidae & Eurotherium & matthesi & 77 \\
\hline Hyaenodontidae & Galecyon & chronius & 78 \\
\hline Hyaenodontidae & Galecyon & peregrinus & 78 \\
\hline Hyaenodontidae & Hyaenodon & rossignoli & 79 \\
\hline Hyaenodontidae & Kerberos & langebadreae & 79 \\
\hline Hyaenodontidae & Masrasector & ligabuei & 80 \\
\hline Hyaenodontidae & Matthodon & tritens & 77 \\
\hline Hyaenodontidae & Paenoxyaenoides & liguritor & 77 \\
\hline Hyaenodontidae & Paracynohyaenodon & schlosseri & 77 \\
\hline Hyaenodontidae & Parapterodon & lostangensis & 81 \\
\hline Hyaenodontidae & Paroxyaena & galliae & 82 \\
\hline Hyaenodontidae & Paroxyaena & pavlovi & 82 \\
\hline Hyaenodontidae & Praecodens & acutus & 81 \\
\hline Hyaenodontidae & Protoproviverra & palaeonictides & 77 \\
\hline Hyaenodontidae & Quercytherium & simplicidens & 77 \\
\hline Hyaenodontidae & Quercytherium & tenebrosum & 77 \\
\hline Hyaenodontidae & Sivapterodon & lahirii & 79 \\
\hline
\end{tabular}




\begin{tabular}{|c|c|c|c|}
\hline Hyanidae & Chasmaporthetes & exitelus & 83 \\
\hline Hyanidae & Crocuta & eturono & 84 \\
\hline Hyanidae & Hyaenictitherium & pilgrimi & 83 \\
\hline Hyanidae & Ictitherium & Iberium & 83 \\
\hline Hyanidae & Lycyaena & macrostoma & 83 \\
\hline Hyanidae & Lycyaenops & rhomboideae & 83 \\
\hline Hyanidae & Palinhyena & reperta & 83 \\
\hline Hyanidae & Proteles & amplidentus & 56 \\
\hline Hyanidae & Protictitherium & punixum & 56 \\
\hline Mephetidae & Promephitis & majori & 85 \\
\hline Mephetidae & Promephitis & malustenensis & 85 \\
\hline Mephetidae & Promephitis & qinensis & 85 \\
\hline Miacidae & Dawsonicyon & Isami & 86 \\
\hline Miacidae & Gracilocyon & rosei & 87 \\
\hline Miacidae & Gracilocyon & rundlei & 88 \\
\hline Miacidae & Gracilocyon & solei & 87 \\
\hline Miacidae & Paramiacis & teilharti & 89 \\
\hline Miacidae & Quercygale & angustidens & 88 \\
\hline Miacidae & Quercygale & hastingsiae & 88 \\
\hline Miacidae & Quercygale & helvetica & 88 \\
\hline Miacidae & Quercygale & smithi & 88 \\
\hline Miacidae & Uintacyon & gingerichi & 88 \\
\hline Miacidae & Uintacyon & hookeri & 88 \\
\hline Miacidae & Vassacyon & bowni & 90 \\
\hline Miacidae & Vassacyon & prieuri & 30 \\
\hline Miacidae & Vassacyon & taxidiotis & 88 \\
\hline Miacidae & Xinyuictis & tenius & 90 \\
\hline Miacidae & Zodiocyon & zetesios & 91 \\
\hline Mustelidae & Aonyx & indicus & 92 \\
\hline Mustelidae & Enhydriodon & afman & 93 \\
\hline Mustelidae & Eomellivora & hungarica & 94 \\
\hline Mustelidae & Ferinestrix & rapax & 95 \\
\hline Mustelidae & Leptarctus & bozemanensis & 96 \\
\hline Mustelidae & Leptarctus & timmi & 96 \\
\hline Mustelidae & Lutraeximia & umbra & 97 \\
\hline Mustelidae & Pannonictis & pliocaenica & 98 \\
\hline Mustelidae & Schultzogale & inexpecta & 99 \\
\hline Mustelidae & Sivaonyx & senutae & 100 \\
\hline Mustelidae & Sivaonyx & soriae & 100 \\
\hline Unassigned Musteloidea & Legionarictis & fortidens & 101 \\
\hline Unassigned Musteloidea & Luogale & rusingensis & 56 \\
\hline Unassigned Musteloidea & Mustelictis & olivieri & 102 \\
\hline Unassigned Musteloidea & Mustelictis & piveteaui & 103 \\
\hline Nimravidae & Dinailurictis & bonali & 104 \\
\hline Nimravidae & Eofelis & edwardsii & 105 \\
\hline Nimravidae & Eofelis & giganteus & 105 \\
\hline Nimravidae & Hoplophoneus & villebramarensis & 104 \\
\hline Nimravidae & Maofelis & cantonensis & 106 \\
\hline Nimravidae & Quercylurus & major & 104 \\
\hline Procyonidae & Amphinasua & lutaria & 107 \\
\hline Procyonidae & Chapalmalania & ortognatha & 107 \\
\hline Procyonidae & Cyonasua & argentina & 107 \\
\hline
\end{tabular}




\begin{tabular}{|c|c|c|c|}
\hline Procyonidae & Pseudobassaris & riggsi & 108 \\
\hline Stenoplesictidae & Stenogale & intermedia & 109 \\
\hline Stenoplesictidae & Stenoplesictis & crocheti & 110 \\
\hline Stenoplesictidae & Stenoplesictis & muhoronii & 56 \\
\hline Ursidae & Adelpharctos & ginsburgi & 111 \\
\hline Ursidae & Agriarctos & gaali & 112 \\
\hline Ursidae & Agriarctos & vighi & 112 \\
\hline Ursidae & Agriotherium & myanmarensis & 113 \\
\hline Ursidae & Arctotherium & angustidens & 114 \\
\hline Ursidae & Arctotherium & vetustum & 114 \\
\hline Ursidae & Cephalogale & geoffroyi & 115 \\
\hline Ursidae & Cephalogale & gergoviensis & 115 \\
\hline Ursidae & Cyonarctos & dessei & 115 \\
\hline Ursidae & Filholictis & filholi & 115 \\
\hline Ursidae & Kretzoiarctos & beatrix & 112 \\
\hline Ursidae & Phoberogale & bonali & 115 \\
\hline Ursidae & Phoberogale & minor & 115 \\
\hline Ursidae & Ursavus & tedfordi & 116 \\
\hline Viverravidae & Bryanictis & paulus & 117 \\
\hline Viverravidae & Protictis & minor & 117 \\
\hline Viverravidae & Protictis & simpsoni & 117 \\
\hline Viverravidae & Viverriscus & omnivorus & 118 \\
\hline Viverridae & Civettictis & howelli & 56 \\
\hline Viverridae & Kenyalutra & songhorensis & 56 \\
\hline Viverridae & Legetetia & Nandii & 56 \\
\hline Viverridae & Mioparadoxurus & meini & 119 \\
\hline
\end{tabular}

Table S9: Sources for morphological and genetic data within groups.

\begin{tabular}{lll}
\hline Group & Genetic data & Morphological data \\
\hline Overall phylogeny & 54 & $30,53,91,120,121,122$ \\
Carnivora: Amphicyonidae & - & 123,124 \\
Carnivora: Barbourofelidae & - & 125 \\
Carnivora: Canidae & 126 & 127,128 \\
Carnivora: Felidae & 129 & $75,130,131,132$ \\
Carnivora: Hyanidae & 133 & 83 \\
Carnivora: Musteloidea & 60 & $95,134,135,136,137$ \\
Carnivora: Nimravidae & - & 104 \\
Carnivora: Pinnipedia & 138 & $139,140,141,142,143,144$ \\
Carnivora: Ursidae (analysed & 145 & 112,146 \\
in combination with & & \\
Amphicynodontinae) & & 119 \\
Carnivora: Viverridae & - & $29,147,148$ \\
Creodonta: Hyaenodontidae & - &
\end{tabular}

Table S10: Topological constraints.

Constraint Carnivora: Amphicyonidae


Haplocyoninae paraphyletic

Temnocyon paraphyletic

Temnocyon altigenis, Temnocyon ferox and Temnocyon subferox monophyletic

Daphoenodon and Borocyon sistergenera

149

150

150

151

151

152

Biogeography

Biogeography

Support in

preliminary

analysis with

outgroup 0.91

\section{Carnivora: Barbourofelidae}

Overall placement as sister to Felidae

\section{Carnivora: Canidae}

Phlaocyon taylori sister to Phlaocyon achoros and Phlaocyon multicuspus

58

Osbornodon scitulus sister to Osbornodon iamonensis, Osbornodon brachypus and

Osbornodon fricki

Vulpes pallida sister to Vulpes chama

155

Vulpes velox sister to Vulpes macrotis

Vulpes corsac, Vulpes bengalensis and Vulpes ferrilata monophyletic

Biogeography

Vulpes

\section{Carnivora: Felidae}

Proailurus most basal in family followed by Hyperailurictis

Pseudailurus quadridentatus most basal in Machairodontinae

Miocene members of extant genera (Felis christoli, Lynx longignathus, Lynx proterolyncis,

and Puma pardoides) placed freely within the subfamily rather than necessarily within

their genus

Felis lunensis sister to Felis silvestris and Felis bieti.

Diamantofelis ferox sister to Namafelis minor

Panthera gombaszoegensis sister to Panthera onca.

Miracinonyx potentially nested within Puma

Dinofelis aronoki sister to Dinofelis piveteaui

Leopardus amnicola sister to Leopardus wiedii

3

\section{Carnivora: Herpestidae}

Extant Asian Herpestes monophyletic relative to African species of the genus 161

Dologale sister to Helogale

Bdeogale jacksoni sister to Bdeogale nigripes

Bdeogale crassicauda sister to Bdeogale omnivora

155

African Herpestides monophyletic

Biogeography

\section{Carnivora: Hyanidae}

Relationship between most genera not included in the cladistics analysis based on the taxonomic hypothesis from this source

Werdelinus placed within the clade containing Belbus to Crocuta since it was a bone crusher based on the species description.

African Hyaenictis constrained monophyletic

Biogeography

African Hyaenictitherium constrained monophyletic 
Ailurinae (Ailurus, Magerictis, Pristinailurus and Parailurus) and Simocyoninae

164

(Protursus, Protursus and Alopecocyon) each monophyletic and sisters

Parailurus anglicus sister to Parailurus hungaricus

164

Amphictis paraphyletic and basal to Ailurinae and Simocyoninae

164

Amphictis prolongata, Amphictis wintershofensis, and Amphictis cuspida combined

164

monophyletic

Parailurus sister to Ailurus

165

Magerictis sister to Parailurus and Ailurus

165

166

Simocyon marshi sister to Simocyon primigenius

Biogeography

\section{Carnivora: Musteloidea: Mephitidae}

Brachyopsigale dubius sister to Brachyprotoma obtusata

Conepatus humboldtii sister to Conepatus semistriatus

155

Spilogale putorius sister to Spilogale angustifrons

155

American species of the family considered monophyletic

Biogeography

\section{Carnivora: Musteloidea: Procyonidae}

Procyon cancrivorus most basal in genus (among extant species)

155

American species of the family considered monophyletic
Namibictis senuti sister to Mellalictis mellalensis sisters

56

Hoplictis, Ischyrictis, and Laphictis combined monophyletic since they often are called subgenera

Martes occulta, Martes diluviana, Martes paleosinensis, Martes pennanti constrained monophyletic (subgenus Pekania) but not constrained to be within the genus Martes Martes gwatkinsii sister to Martes flavigula

Mustela nivalis, M. subpalmata, M. russelliana and $M$. tonkinensis monophyletic

Tribe Aonychini (Aonyx, Cyrnaonyx, and Limnonyx) monophyletic

Tribe Lutrini (Algarolutra, Lutra (excluding some fossil forms), Lutrogale, Lutravus,

Lutraeximia, Mionictis, Paralutra, Pteronura, Sardolutra, Satherium and Siamogale) monophyletic

Enhydriodontini (Enhydriodon ,Paludolutra, Sivaonyx and Vishnuonyx) monophyletic Satherium sister to Pteronura

Algarolutra, Megalenhydris, Sardolutra and Lutraeximia nested within Lutra

Sardolutra sister to Lutra castiglionis

168

Pekenia outside

Martes in 60

155

3

59

59

100

169

170

170

97

171

Lutra simplicidens sister to Lutra fatimazohrae

172

Biogeography

American species of Aonyx constrained to be monophyletic

\section{Carnivora: Nimravidae}

Hoplophoneus mentalis sister to Hoplophoneus primaevus

104

\section{Carnivora: Percrocutidae}

Relationship of most species given by

((Dinocrocuta salonicae, Dinocrocuta senyureki), (Dinocrocuta gigantea, Dinocrocuta

algeriensis $)$ ), ((Percrocuta abessalomi, Percrocuta tobieni), (Percrocuta miocenica,

(Percrocuta tungurensis, Percrocuta carnifex)))

African Percrocuta constrained monophyletic

Biogeography

\section{Carnivora: Pinnepedia}

Assignment of Puijila, Semantor, Potamotherium, and Enaliarctidae as basal to other

families

Assignment of Kolponomos within the group of basal species mentioned above

Pteronarctos and Pacificotaria sistergenera. Enaliarctos sister to both 


\section{Carnivora: Ursidae (and Amphicynodontidae)}

Amphicynodontidae paraphyletic and basal to Ursidae

(Amphicynodon brachyrostris, (Amphicynodon crassirostris, Amphicynodon typicus),

(Amphicynodon velaunus, Amphicynodon leptorhynchus, (Amphicynodon teilhardi,

(Amphicynodon cephalogalinus, Amphicynodon gracilis)))). Amphicynodon chardini

placed freely in the genus

Phoberocyoninae sister to Hemicyoninae

Plionarctos sister to Tremarctos

Arctodus sister to Arctotherium

Arctodus and Arctotherium sister to Plionarctos and Tremarctos

Ursus etruscus basal to $U$. arctos, U. maritimus and U. spelaeus

Ursus boeckhi basal to remaining Ursus, Helarctos, and Melursus

180

\section{Carnivora: Viverridae}

Euboictis and Legetetia sistergenera

Semigenetta elegans, Semigenetta laugnacensis and Semigenetta sansaniensis considered

56

monophyletic

Arctictis, Arctogalidia, Macrogalidia, Mioparadoxurus, Paguma, Paradoxurus constrained to be monophyletic

Genetta abyssinica sister to Genetta thierryi

155

Viverra civettina sister to Viverra megaspila

\section{Carnivoramorpha: Viverravidae}

Ictidopappus most basal in the family (except for perhaps Pappictidops and Pristinictis)

Simpsonictis closer to Viverriscus than any other genus (except for perhaps Pappictidops

and Pristinictis)

Bryanictis closer to Intyrictis than any other genus (except for perhaps Pappictidops and

Pristinictis)

Bryanictis, Intyrictis, Protictis and Raphictis monophyletic (although Pappictidops and

Pristinictis are allowed to be placed freely in the family)

\section{Creodonta: Hyaenodontidae}

North American Arfia constrained monophyletic

European Prototomus constrained monophyletic

Machaeroidinae basal to other subfamilies.

\section{Creodonta: Oxyaenidae}

Part of family resolved as (Dipsalodon churchillorum, (Dipsalodon matthewi,

(Ambloctonus, (Palaeonictis peloria, (Palaeonictis gigantea, (Palaeonictis occidentalis,

Palaeonictis wingi)))))). Sarkastodon and Malfelis free-floating within the subfamily

Part of family resolved as (Dipsalidictis aequidens, (Dipsalidictis krausei, Dipsalidictis

platypus, (Dipsalidictis transiens, ((((Oxyaena gulo, (Oxyaena forcipata, Oxyaena intermedia)), Oxyaena woutersi), ((Patriofelis ferox, Patriofelis ulta), Protopsalis tigrinus)))))). Sarkastodon and Malfelis free-floating within the subfamily. Oxyaena lupina, Oxyaena pardalis, and Oxyaena simpsoni free-floating within the genus 
Figure S1: Effect of incomplete sampling on diversity estimates.

The difference in median species and phylogenetic diversity either globally or for individual continents. Due to the limited effect of limited sampling, the two lines are frequently on top of each other and the line for incomplete sampling is therefore stippled to make both lines visible.
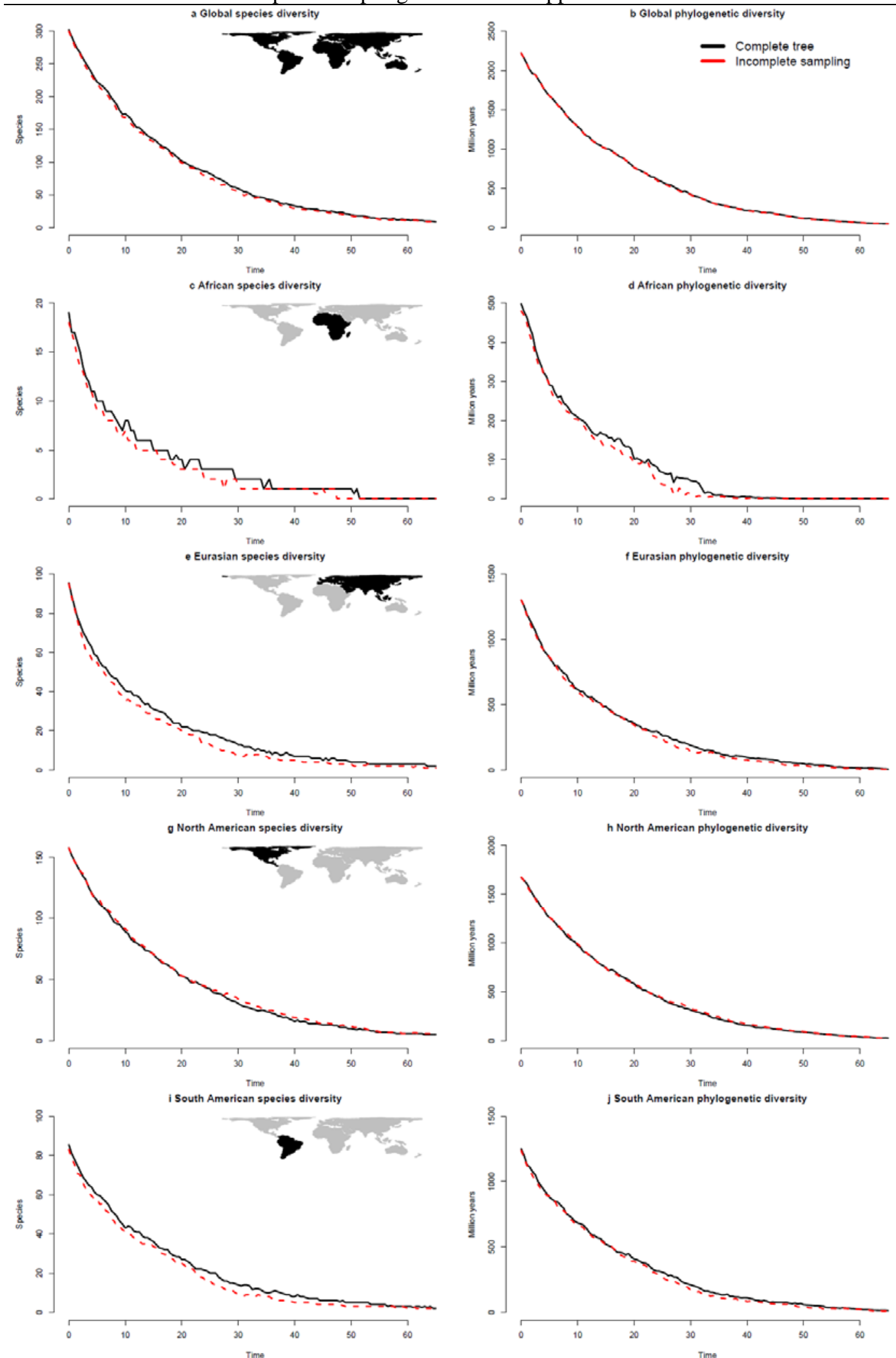


\section{Figure S2: Simulation model.}

Schematic drawing of the simulation model, which is a seven classes ClaSSE model transformed into a four-area version of a GeoSSE model. All arrows drawn in full (dispersal rate, extinction rate and allopatric speciation rate) represent cases where the species in question changes class in the ClaSSE model (or completely disappears for extinction from single area classes), whereas stippled lines (sympatric speciation rate and jump dispersal speciation rate) represent cases where the species buds off from another species while the ancestor stays in the region it was before.

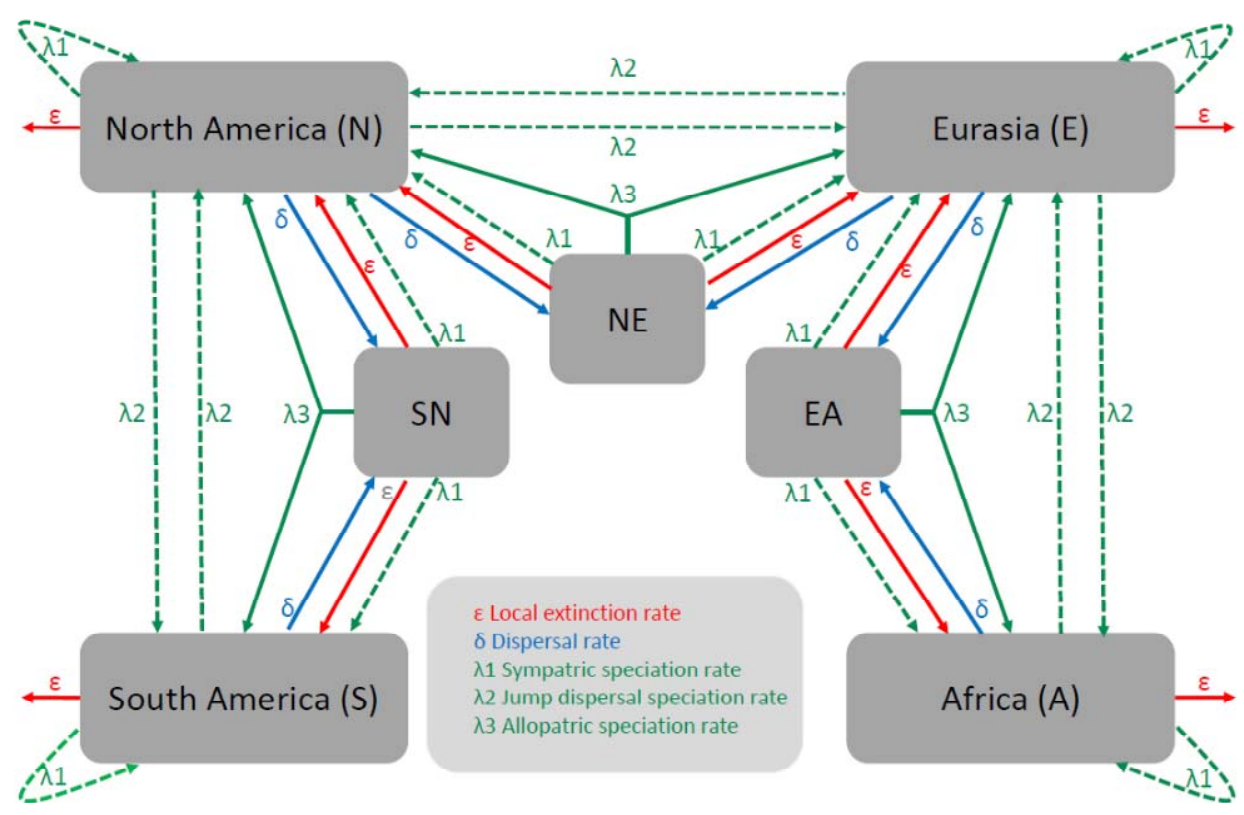

